\title{
RESTAURACIÓN DE HÓRREOS EN EL VALLE DE VALDEÓN (LEÓN). AÑOS 1988-1992
}

\author{
(RESTORATION OF GRANARIES IN THE VALDEÓN VALLEY, LEÓN. 1988-1992)
}

\author{
Enrique Luelmo Varela, Arquitecto \\ Promueve: Junta de Castilla y León. Diputación Prov. de León
}

Fecha de recepciön: 31-I-95

\begin{abstract}
RESUMEN
El presente trabajo tiene por objeto la descripción de la actuación de restauración de hórreos en el valle de Valdeón (León), llevada a cabo en los años 1986 a 1992 por la Junta de Castilla y León en colaboración con la Diputación Provincial de León y bajo la dirección técnica del autor. Se pretendió con ello la conservación de un tipo arquitectónico singular del valle - protegido desde el año 1985 con consideración de Bien de Interés Cultural por la Junta de Castilla y León - en claro proceso de abandono e infravaloración por parte de sus propietarios, como resultado de la obsolescencia de su primitivo uso. Se planteó como una actuación piloto que al tiempo que sentaba los criterios de posibles intervenciones futuras de mantenimiento de iniciativa particular o pública, incidiera en el necesario cambio de mentalidad de la población autóctona respecto a su patrimonio arquitectónico.
\end{abstract}

La ejecución de la obra ha seguido criterios eminentemente prácticos y dictados por el hacer de los oficios tradicionales intervinientes (lejos, por tanto, de planteamientos puristas o teóricos), intentando llegar a un amplio número de ejemplares y lógicamente, a los más deteriorados.

Tras una introducción y descripciòn del contexto de la actuación, se describen los hórreos de la Península Ibérica como marco genérico en que situar los que nos ocupan,se pasa a continuación a la descripción detallada de estos últimos y de su patología. Seguidamente se detalla la intervención realizada y se exponen las conclusiones.

\section{SUMMARY}

The present article aims to describe the restoration of the (raised) granaries in the Valdeón valley (León) carried out from 1988 to 1992 by the Junta de Castilla y Leon in collaboration with the Diputación Provincial de León and under the technical direction of the author of the article.

The goal of the restoration was to preserve a unique architectural type of the valley - protected since 1985 by the Junta de Casilla y León as Property of Cultural Interest - at that time clearly affected by an attitude of abandonment and underestimation of its owners, as a result of the obsolescence of its original use. This action was undertaken with the idea of a pilot actuation that would similtaneosly establish the criteria for possible future maintenance (public or private) actions, and initiate the necessary change of mentality of the autochtonous population towards their architectural heritage.

The execution of the work followed, before all, the practical criteria suggested by the participating traditional crafts (therefore, far from purist or theoretical standpoints), and tried to reach a large number of granaries, and logically, the most damaged ones.

The work is divided into two stages: in the first one, following an introduction and description of the context of performance, the granaries of the Iberian Peninsula are described as a general framework containing those which ware subject of our study, describing the latter and their pathology in detail. The second part contain the detailed description of the actions undertaken (their criteria and typology) and the conclusions.

\section{1 - Introducción}

En aplicación de sus competencias específicas (Ley del Patrimonio Histórico-ArtísticoEspañol 16 / 1985 de 25 de Junio y Decreto de la Junta de Castilla y León 69/1984 de 2 de Agosto por el que se declaran los hórreos de la
Comunidad como Bienes de Interés Cultural, quedando por tanto protegidos), la Junta de Castilla y León en conjunción con la Diputación Provincial de León, desarrollaron en cinco campañas de verano, entre los años 1988 a 1992, la actuación de rehabilitación de los hórreos del valle de Valdeón, sito en el extremaNE de la provincia de León, en el ámbito de los Picos de Europa. 
A cargo del primer organismo corrieron los campos de trabajo para jóvenes, que de forma paralela y como apoyo a las obras de restauración, se desarrollaron en la localidad de Soto de Valdeón, siendo la Diputación el organismo promotor de las obras. Con este fin se contrató cada verano un equipo de operarios formado por un responsable o coordinador de los trabajos, dos oficiales carpinteros, eventualmente un oficial y uno o dos peones de albañilería y un cantero. La supervisión técnica de los trabajos corrió siempre a cargo de un arquitecto (el que esto suscribe, sustituido en la campaña de 1991 por el también arquitecto Eloy Algorri García), contratadoasímismo por la Diputación Provincial.

La programación de la intervención se hizo con la voluntad de atender el máximo posible de unidades (dentro de las limitaciones de tiempo y presupuesto) y entre ellas, a las más deterioradas. Se comenzó la actuación por los dos núcleos del valle en que se daban ambas circunstancias y cuya proximidad permitía una mayor operatividad, Soto de Valdeón y Caldevilla (años 1988, 1989 y 1990), continuándose con Posada de Valdeón y el núcleo inmediato de Los Llanos (1991) y finalizando con Prada (1992). En total se intervino en 47 unidades de las 85 existentes en el valle, con un presupuesto total de obra para las cinco campañas de 22.000 .000 pts.

\section{2 - El contexto}

El valle de Valdeón se sitúa en el extremo NE de la provincia de León, encajadoentre las vertientes meridionales de los macizos central y occidental de los Picos de Europa y la Cordillera Cantábrica. Morfológicamente se corresponde con una $\mathrm{Y}$ invertida, cuyos brazos dan origen al río Cares que divide los macizos citados llevando aguas a Asturias. En el centro de la Y se sitúa Posada de Valdeón, capital del valle que alberga un total de 8 núcleos poblados con un total de 496 habitantes (datos de 1991).

La economía se puede definir como de subsistencia, típica de las áreas de montaña, con ganadería de bovino y ovino para producción lechera, y agricultura basada en los prados y pastos para producción de forraje y pequeños huertos para el consumo privado. El aprovechamiento forestal y los permisos de caza constituyen aportaciones básicas en el presupuesto municipal. En los últimos años ha adquirido gran relevancia la actividad hostelera basada en la actividad turística y de esparcimiento ligada a la naturaleza (especialmente en época estival), dado el atractivo del entorno, actividad que se perfila claramente como el sustituto del sector agroganadero tradicional. En un futuro y a raíz de la integración en el mercado europeo, es de suponer que esta tendencia se acentuará, debatiéndose actualmente por parte de las Administraciones y entidades implicadas la figura de protección y ordenación que regulará las actividades de la zona en los próximos años
Como es habitual en muchas áreas de montaña, la regresión y el despoblamiento del área en los últimos 35 años es notoria (emigración a los polos industriales en zonas periféricas y centro peninsular, a Europa y América), con el consiguiente envejecimiento de la población (otro importante recurso económico lo constituyen en la actualidad las pensiones y jubilaciones), abandono de los cultivos tradicionales (especialmente el grano, sustituido por los piensos preparados), abandono de gran parte del parque edificatorio y consiguiente pérdida de los oficios y técnicas constructivas tradicionales (carpinteros, canteros, etc) así como de los conocimientos constructivos ligados a las mismas. En los últimos 10 años se produce una paulatina ocupación con vivienda de segunda ocupación (motivada por el retorno durante el período estival de la generación que emigró) y de sustitución de la vivienda tradicional, extendiéndose las nuevas técnicas constructivas (hormigón. uralita, etc) ajenas a los materiales y sistemas tradicionales $\mathrm{y}$ acentuando el proceso descrito.

Los hórreos constituyen un elemento más de la arquitectura de apoyo a la vivienda y a la explotación agroganadera (como son los molinos, alpendres, cuadras, pajares, hornos, etc), siendo un tipo edificatorio característico del valle, que no escapa al proceso general arriba descrito, como consecuencia de la obsolescencia de su primitivo uso como granero y el consiguiente abandono y pérdida de su valoración por parte de los propietarios. Ello origina su deterioro y cambio de uso (actualmente la mayoría se utilizan como despensa, trastero de enseres inutilizados, secadero de ropa y como "garaje" del coche) y en ocasiones conlleva la alteración morfológica y de materiales de un elemento que por su esencialidad y elementalidad conceptual, constructiva y volumétrica, admite mal los cambios.

A partir del principio elemental del necesario uso de toda arquitectura para su mantenimiento y conservación, así como de la evidente dificultad de encontrar alternativas sustitutorias al uso original (en un tipo edificatorio tan especializado), se propuso la posible utilización de los hórreos como elementos de apoyo ocasional a la oferta hostelera del valle en la época estival y enfocado a un segmento específico de la población de posibilidades económicas más limitadas (montañeros y excursionistas jóvenes, etc), que permitiera a sus propietarios la rentabilización, cuando menos, de su mantenimiento. Hasta el momento sólo conocemos dos casos en que esto se haya llevado a la práctica, siendo positiva la experiencia de los propietarios.

La intervención que aquí se describe pretendió ser un primer pasoencaminadoal necesario cambiode mentalidad de la población autóctona hacia un elemento tan característico de su patrimonio (y por extensión hacia toda su arquitectura popular) y que sin dudaconstituye uno más de los atractivos o reclamos del valle, intención que de 
momento no se ha conseguido (a lo que quizá contribuyen los recelos que entre los habitantes suscita la protección legal establecida sobre los hórreos y la incertidumbre con que se vive en el valle el actual debate sobre la figura legal de protección y ordenación del conjunto de los Picos de Europa).

Con independencia de la posible y deseable continuación de la actuación de la Administración (bien con acciones divulgativas -catalogación de las unidades existentes, folletos y carteles explicativos, etc- bien con ayudas o subvenciones a los propietarios para su conservación -tal y como se realiza en otras Comunidades Autónomas- o mejor, con ambas actuaciones), parece indispensable el cambio de mentalidad de los propietarios hacia los hórreos, asumiendo que el futuro de estas áreas pasa indefectiblemente por la potenciación y protección de los propios recursosy muy especialmente de los diferenciadores, enfocada a un turismo de calidad y no masivo (al modo de

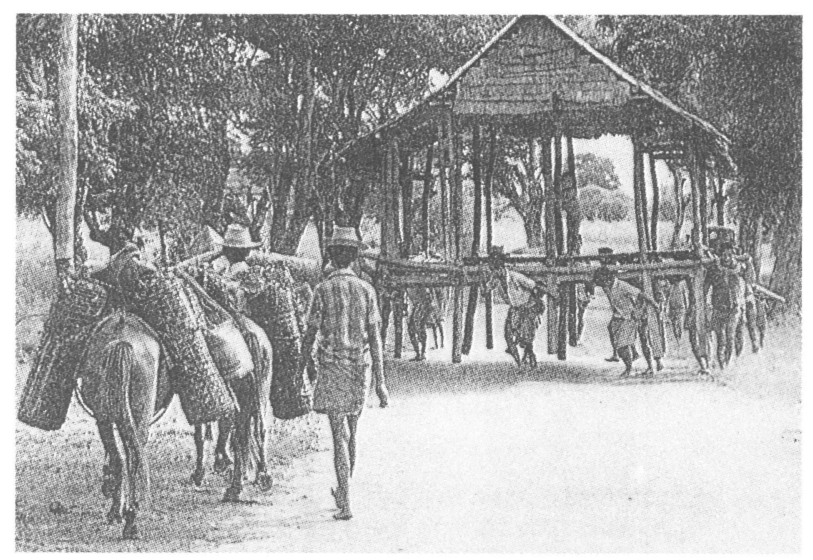

Fig.1.- Traslado del armazón de una casa sobre pilotes en Indonesia por los indígenas. Frankowski, E.- Op. cit. lo realizado en otras áreas de montaña europeas -Alpes, Pirineos, etc.-).

\section{3 - Los hórreos}

\section{1 - Definición, extensión, origen e invariantes.}

Como es sabido los hórreos son cajas (contenedores) de madera elevadas sobre el suelo, que se utilizan (o se utilizaron en un principio), como almacén y secadero del grano en zonas húmedas de cosecha cerealista. Su singularidad arquitectónica parece dada por ese carácter tan específico de "arquitectura móvil" que permite su traslado en prácticamente todas las variantes del mismo (Fig. 1), en base a su sistema constructivo en seco, tipo "mecano". Bajo diversas formas, en función del clima, materiales de construcción disponibles, etc., aparecen en los cinco continentes, como se puede comprobar en cualquier tratado general sobre el tema (Fig. 2), extendiéndose en la Península Ibérica, por Portugal, Galiciay franja Cantábrica, con derivaciones a las provincias limítrofes de la Cordillera en su vertiente meridional (Fig. 3).

El origen de su forma se ha querido ver por algunos autores en las primitivas construcciones palafíticas (Fig. 4) de áreas lacustres y húmedas (hipótesis formalista), frente a otros que lo sitúan en la simple depuración de un tipo constructivo sumamente especializado, en el que la semejanza de condicionantes medioambientales daría lugar a ejemplares muy similares (hipótesis funcionalista), como lo demuestran -por poner un ejemplo directamente relacionado con el tema- los hórreos de Valdeón y los graneros del Valais, cantón alpino de Suiza (Figs. 5 y 6)

Los invariantes físicos que definen el tipo constructivo (ciñéndonos a la Península Ibérica) y que aparecen en prácticamente todas sus manifestaciones, son :

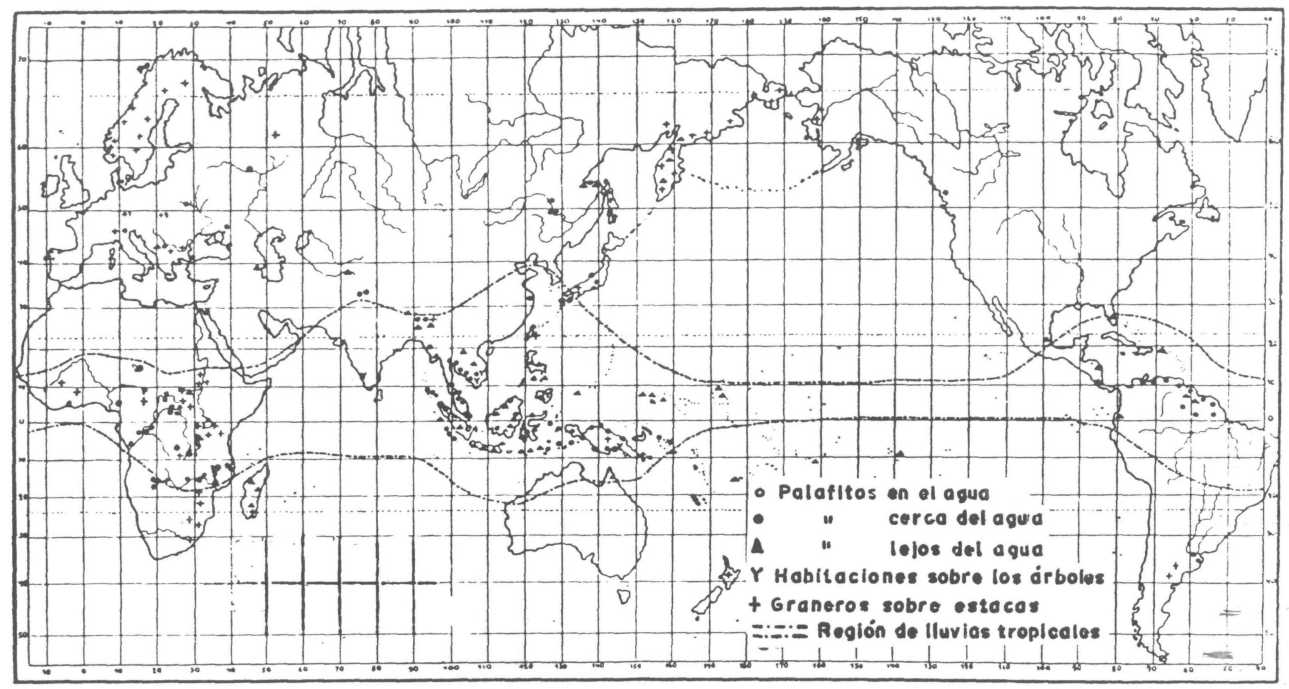

Fig.2.- Distribución mundial de palafitos y graneros sobre estacas.Frankowski, E.- Op. cit. 

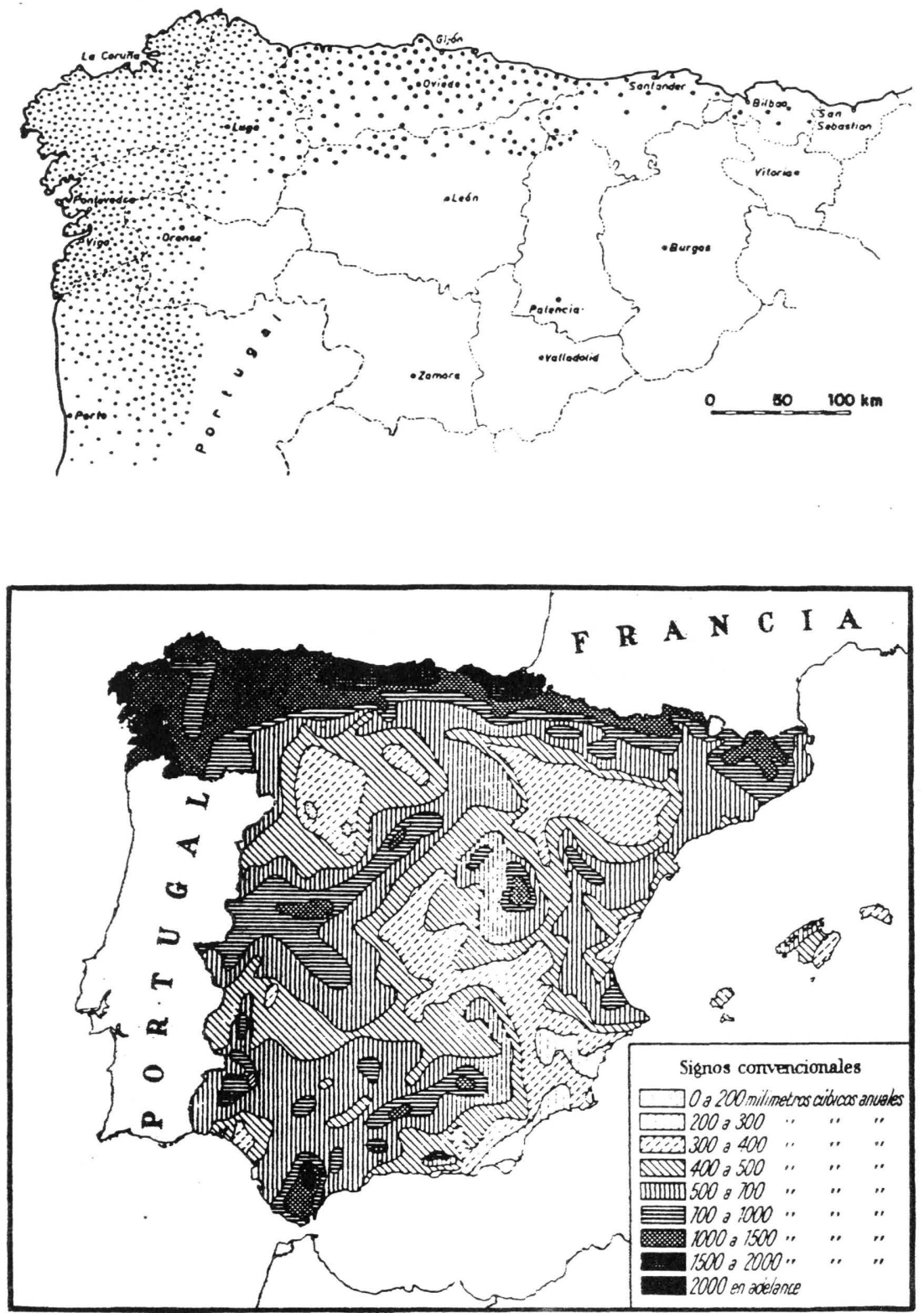

Fig.3.- Distribución geográfica de los hórreos en el NO. de España (arriba). Distribución anual de lluvias en la Peninsula Ibérica: Iberia húmeda (abajo).Frankowski, E.- Op. cit.

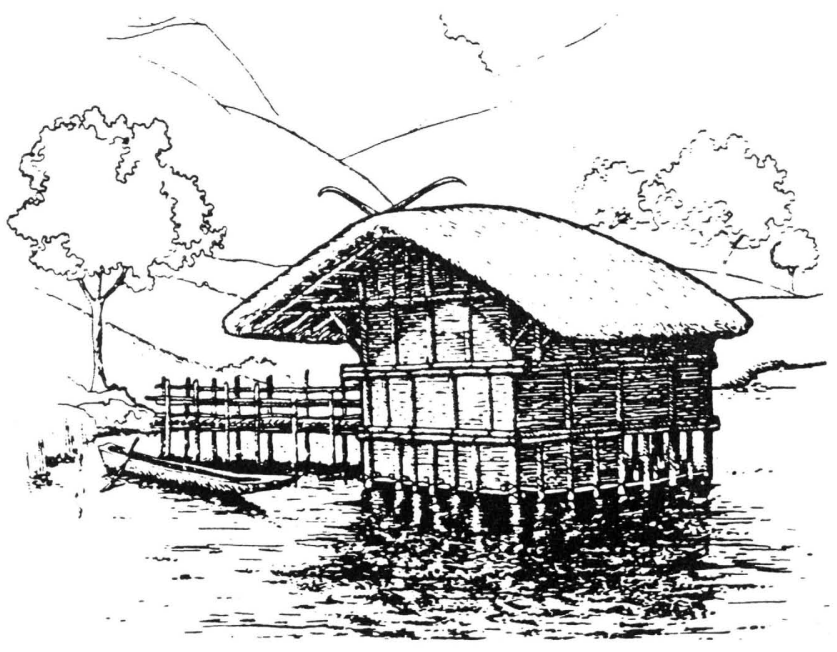

Fig.4.-Reconstrucción ideal de palafito del ámbito lacustre y alpestre del centro de Europa. Frankowski, E.- Op. cit.

(c) Consejo Superior de Investigaciones Científicas Licencia Creative Commons 3.0 España (by-nc)
-Las bases de apoyo de los pies derechos sustentadores de la caja o contenedor (normalmente piedras de gran tamaño que en ocasiones se sustituyen por muros de fábrica).

-Los pies derechos (o muros en su caso, como queda dicho) elevadores de la caja sobre el terreno (con formas variadas y de madera o piedra), rematados por una pieza volada que impide el acceso de roedores y alimañas (normalmente de piedra y con forma cuadrada o circular).

- La caja de almacenamiento del grano con un grado mayor o menor de aireación (de trenzado de ramas o cañas, entablado de madera, cantería, piezas cerámicas, mampostería, bloque, chapa, etc., o de las diversas combinaciones de esos materiales).

-La cubierta de evacuación de aguas y protección, con mayor o menor pendiente y alero (de tepes de hierba, 


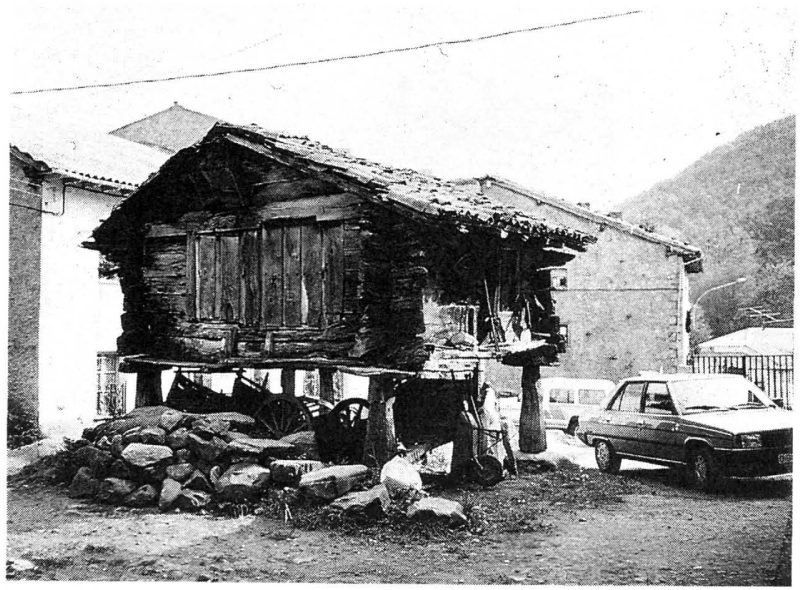

Fig.5.- Hórreo antiguo del valle de Valdeón (León). Autor.

centeno a semejanza de las pallozas, paja, cañizo, tablas, tejas, piedra, chapa, fibrocemento, etc.).

-El acceso, móvil (escala de madera) o fijo(de mampostería, fábrica de ladrillo, etc.).

-El espacio cubierto por el hórreo (en ocasiones delimitado por un muro perimetral de fábrica que puede llegar hasta la caja del hórreo formando una planta baja cerrada, de fábrica de ladrillo, mampostería, etc. y que se puede usar como corral, protección del carro o aperos de faena, bodega, leñera, etc. y actualmente también como garaje).

Las combinaciones de estos elementos (que se pueden considerar ilimitadas), dan lugar a los diferentes tipos y sub-tipos derivados del tipo constructivo básico.

\section{2 - Los tipos de hórreos en la Península Ibérica.}

En el área peninsular, los tipos que aparecen se corresponden con la Iberia húmeda (Fig. 3) y con áreas geográficas suficientemente delimitadas. Lo que sigue no pretende ser otra cosa que un rápido repaso de los tipos genéricos de hórreos que nos permitan encuadrar con visión de conjunto el que nos ocupa, remitiéndose a los tratados especializados para el estudio detallado de los mismos (en la exposición seguiremos un recorrido desde el extremo E. de la franja Cantábrica hasta el S. de Portugal):

\section{I - Garaixe vasco y navarro (Fig. 7 a).}

Prácticamente desaparecido desde el pasado siglo, a causa de la fuerte industrialización de la zona y consiguiente pérdida de la cultura rural. De planta cuadrada o rectangular, y caja de escasa altura (que a veces presenta un segundo piso volado y utilizado como palomar o desván), con cubierta a dos aguas de teja o pizarra y con espacio inferior a veces cerrado para cuadra.

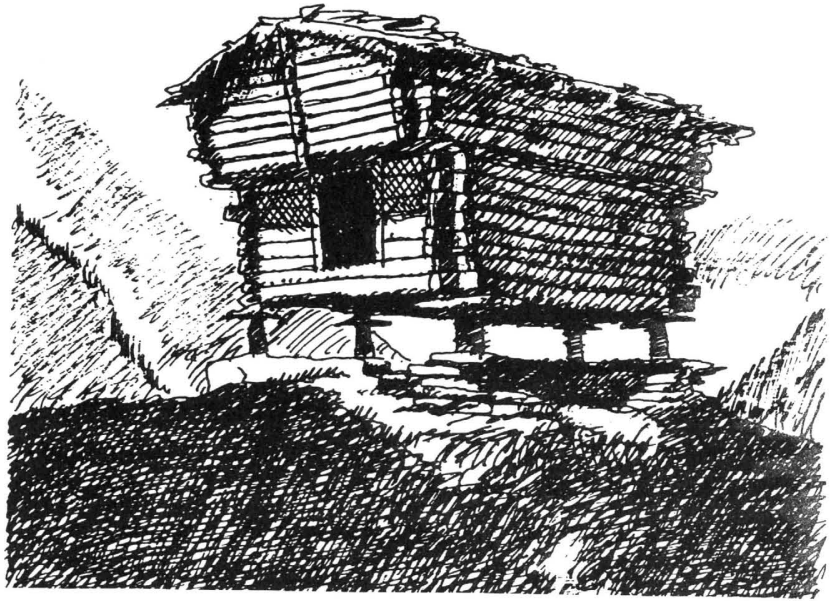

Fig.6.- Granero antiguo del cantón del Valais (Suiza). Dibujo del autor sobre fot. de E. Frankowski

II - Hórreo del área de confluencia de Cantabria, Palencia y León (Fig. 7 c)

Hórreo más austero y elemental que el asturiano, de planta cuadrada y con cubierta a dos o cuatro aguas, caja y alero de tamaño reducido y sin galería perimetral. Con acusado proceso de cambio de uso y disminución del número de ejemplares.

\section{III - Hórreo asturiano (Fig. 7 D,E).}

Cabe decir que en Asturias conviven diversos tipos en correspondencia con las distintas áreas geográficas, considerándose aquí como asturiano el más abundante en las zonas central y oriental (en la occidental convive con los cabazos y canastros y en el extremo SO. con el hórreo de Ancares) y el popularmente más identificado con Asturias. Diremos también que por el gran número de ejemplares, permanenciadel usoy "exportación"a regiones limítrofes, constituye uno de los dos grandes tipos de los hórreos peninsulares (junto con el gallego).

La denominación popular distingue hórreos y paneras, según tengan 4 apoyos y planta cuadrada o 6 o más apoyos y planta cuadrada o rectangular. Estos últimos son de mayor tamaño y mucho menos numerosos, con cubierta a cuatro aguas (normalmente de teja), y amplios vuelos que cobijan una galería perimetral utilizada como secadero del grano. El entablado de la caja presenta en ocasiones motivos ornamentales.

\section{IV - Granero asturiano (Fig. 7 F, G)}

Aunque se podría considerar variante del anterior, se ha preferido independizar dada su singular composición con la vivienda y su localización en un área específica del occidente astur. Se puede definir como un hórreo asturiano superpuesto a una edificación cerrada que, en ocasiones, llega a confundirse con el mismo hórreo, rematando un 


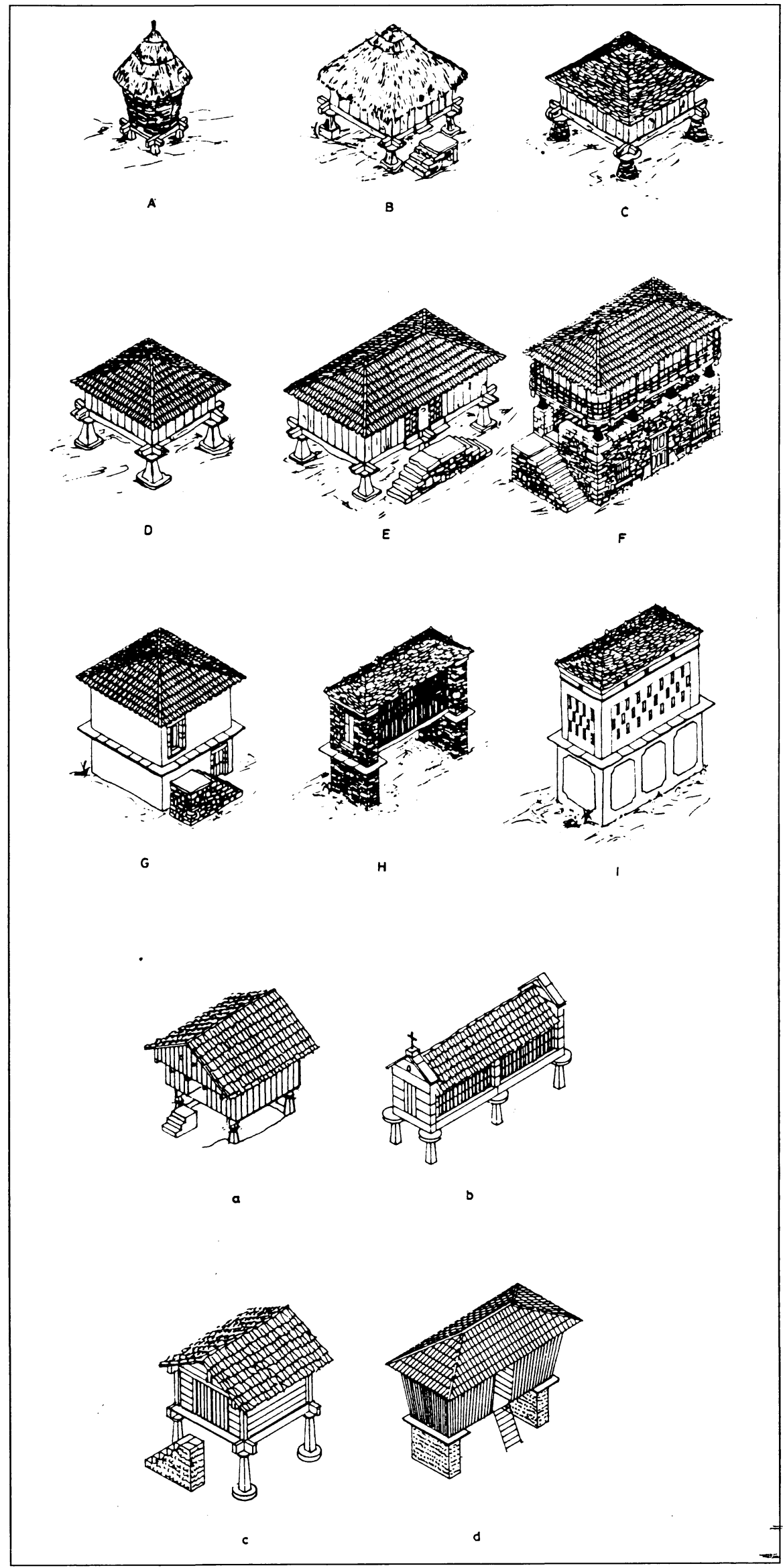

Fig.7.- Tipología de hórreos ibéricos: esquema axonométrico. Cobo, Cores, Zarracina - Op. cit.(mayúsculas). Autor (minúsculas). 
edificio de dos plantas en el que la baja se destina a corral yla primeraa vivienda. La razón de esta singular disposición parece deberse a la limitación del tamaño de la parcela.

\section{V - Cabazo}

Aparece en el área de transición entre Asturias y Galicia y en ambas regiones en coexistencia con los tipos III y IV. Es quizá el tipo más especializado funcionalmente para el curadodel grano por aireación. Se distinguen dos variantes :

-Tipo Ribadeo (Fig. 7 I): de planta rectangular, llega a alcanzar dos o tres alturas, con caja de mampostería de pizarra, espacio inferior cerrado y cubierta a cuatro aguas.

-Tipo Mondoñedo (Fig. 7 H): lo mismo que el anterior, sobre cepas (muros) de fábrica

\section{VI - Hórreo de los Ancares (Fig. 7 B, C).}

Aparece en la confluencia del área gallega, astur y leonesa. De planta cuadrada y menor tamaño que el asturiano, con cubierta a cuatro aguas, de centeno (a semejanza de las pallozas) o pizarra y gran proporción en relación a la caja. Con pies derechos tronco-cónicos de madera y a veces de mampostería de lajas de pizarra.

\section{VII - Hórreo gallego (Fig. 7 b)}

Como se dijo anteriormente, constituye junto con el asturiano, el otro gran tipo (o grupo) de los hórreos peninsulares. El ámbito del mismo es Galicia y norte de Portugal. A diferencia del asturiano el grano se cura dentro de la caja, por lo que ésta presenta forma alargada (en ocasiones exageradamente) con gran número de perforaciones, constituyendo un tipo especialmente diseñado para este fin (parece lógico suponer que la orografía gallega con valles menos encajonados que los asturianos y la mayor intensidad de los vientos de la región han dado lugar a la diferenciación de ambos tipos). Es de menor tamaño que el astur (a veces semejantes a urnas), de cubierta a dos aguas, caja con gran variedad de materiales (si bien son de destacar los de cantería, de espléndida factura, en el área costera atlántica), los pies derechos son casi siempre de piedra, presentando frecuentemente cepas de mampostería o sillería en los frentes o hastiales, o bien el nivel inferior completamente cerrado.

De gran valor plástico y carácter simbólico cuasi-sagrado para el campesino gallego (al menos antiguamente), supera su mera condición de granero, como testifica la abundancia de cruces de remate de los frentes y la profusión de símbolos de carácter religioso que protegen el grano. Es habitual el empleo de colores primarios en las unidades de madera. Son frecuentes las agrupaciones de un gran número de hórreos en áreas exteriores a los núcleos y reservadas a este fin, próximas a la era.
VIII - Canastro (Asturias), Cabaceiro (Galicia) o Palheiro (Portugal) (Fig. 7 A).

$\mathrm{Su}$ ámbito se extiende a las regiones mencionadas, siendo el tipo más elemental y primitivo (quizá origen de la idea de hórreo). De planta circular y pequeño tamaño, con cubierta de paja y caja de varas de roble entretejidas, pies derechos enanos de madera o piedra con piezas de remate de los mismos en piedra.

\section{VIII - Espigueiro (Fig. 7 d).}

Característico de Portugal. La caja presenta a veces paredes inclinadas, de piedra o madera, cubierta de teja, pizarra o paja y pies derechos, cepas o cuerpo inferior cerrado. La forma varía desde el similar al gallego hasta los de gran tamaño.

\section{4 - Los hórreos del valle de Valdeón}

\section{I - Variantes, datación e implantación.}

Los hórreos del extremo NE. de la provincia de León (en los que se engloban los del valle de Valdeón, el vecino valle de Sajambre y el área de Riaño, Mampodre y NE. de Cistierna), considerados por algunos autores como una variante del asturiano, presentan dos sub-tipos o variantes: el de cubierta a dos aguas y el de cuatro aguas (Figs. 8,9 y 10). Ambos son de planta cuadrada (de aproximadamente 3,50 a $5,50 \mathrm{~m}$ de lado; altura sobre suelo que varía entre 1,50 y $2,00 \mathrm{~m}$ y altura de caja de aproximadamente $1,60 \mathrm{~m}$ ) y sustentación sobre cuatro apoyos (en muy raras ocasiones se ven ejemplares de 6 o más apoyos -paneras- en los hórreos de mayores dimensiones).

El de dos aguas se puede decir que es el tipo más genuino y específico del área (si bien aparece también en valles de Cantabria -Pas, Liébana, etc.- y del NO. de la provincia de Palencia - Guardo, etc.), siendo quizá el resultado de la adaptación al sistema tradicional y habitual de construcción de las cubiertas (tabla ripia sobre cabios y teja árabe) en las edificaciones locales. Son particularmente interesantes los hórreos más antiguos del valle (pertenecientes a este subtipo y que nos lo muestran como el más primitivo), con las tablas de la caja autoportantes y trabadas en las esquinas (Fig. 5).

E1 de cuatro aguas es el que presenta mayor similitud formal con el asturiano (Fig. 11), pudiendo verse como un hórreo más pobre o elemental (de apariencia más desnuda y austera) que aquél, manifestándose en el menor tamaño, menor vuelo de aleros, ausencia (normalmente) de galería perimetral y barandillas y elementos ornamentales raros de encontrar. Bien pudiera ser una derivación del de dos aguas a raíz del trabajo en el valle en épocas más recientes de carpinteros asturianos (hay que tener en cuenta que el valle 


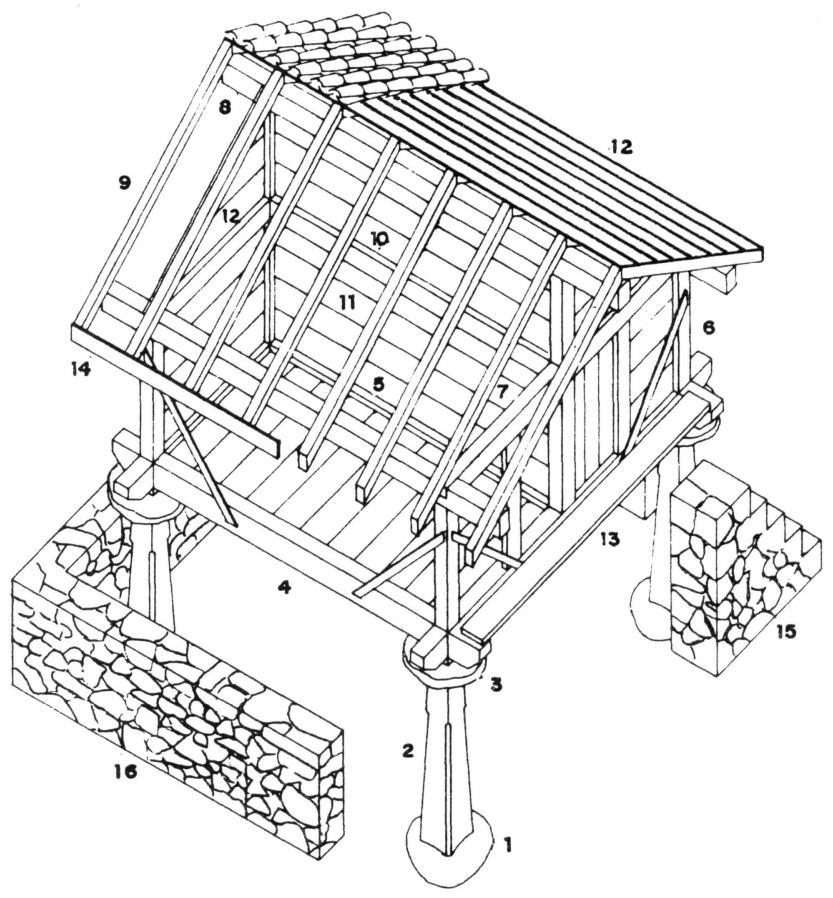

1.- Solera. 2.- Pegollo. 3.- Torna-ratas. 4.- Trave. 5.- Viga media. 6.Cantonera. 7.- Sobre-trave. 8.- Viga cumbre. 9.- Cabio. 10.- Viga divisoria. 11.- Tabique divisorio. 12.- Tablero. 13.- Tanobia. 14.- Mandríl. 15.Escalera acceso. 16.- Muro delimitador.

Fig.8.- Hórreo-tipo de cubierta a dos aguas del valle de Valdeón (León): esquema axonométrico. Autor.

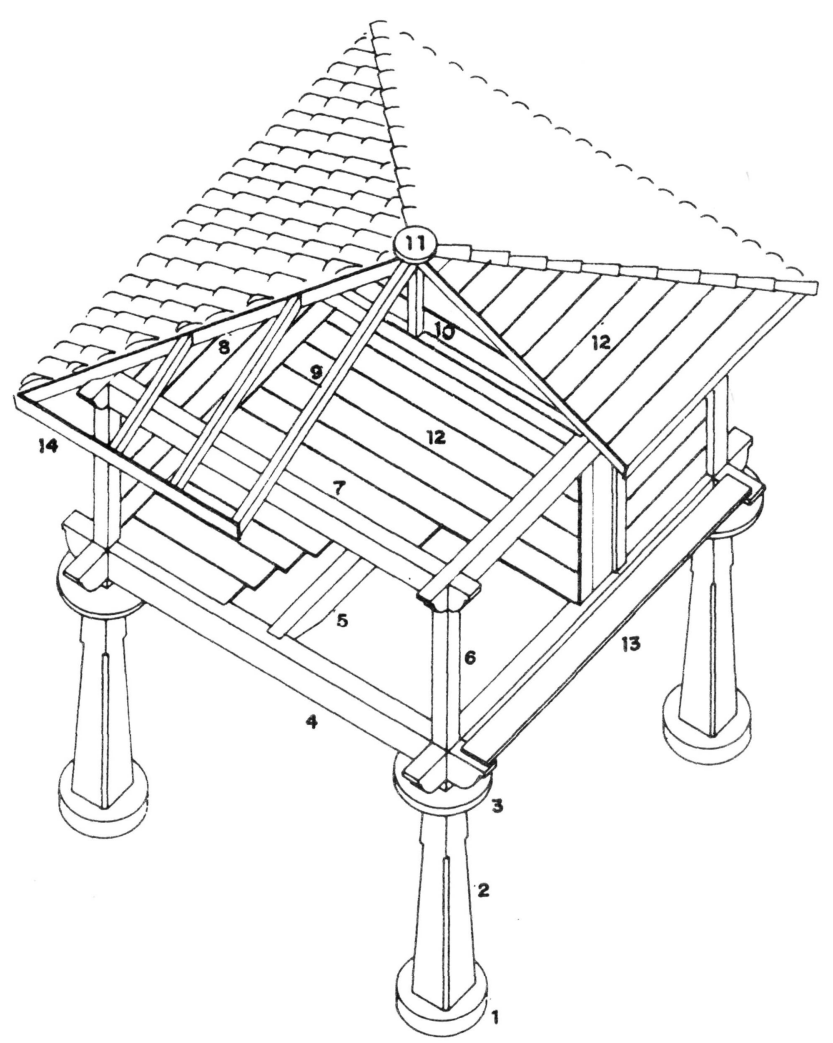

1.- Solera. 2.- Pegollo. 3.- Toma-ratas. 4.- Trave. 5.- Viga media. 6.Cantonera. 7.- Sobre-trave. 8.- Aguilón. 9.- Cabio. 10.- Curbatón. 11.Loncha cimera. 12.- Tablero machihembrado. 13.- Tanobia. 14.- Mandríl.

Fig.9.- Hórreo-tipo de cubierta a cuatro aguas del valle de Valdeón (León): esquema axonométrico. Autor.

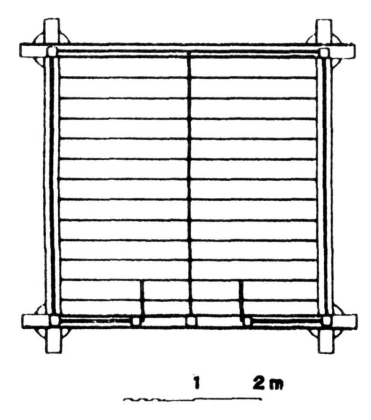

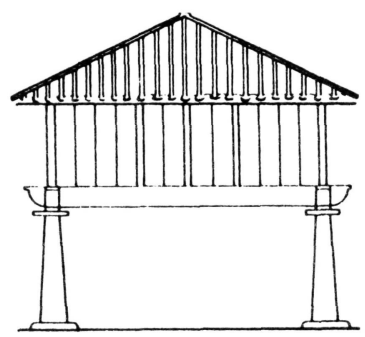

TIPO

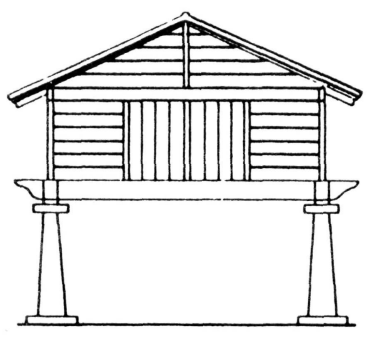

TIPO 2
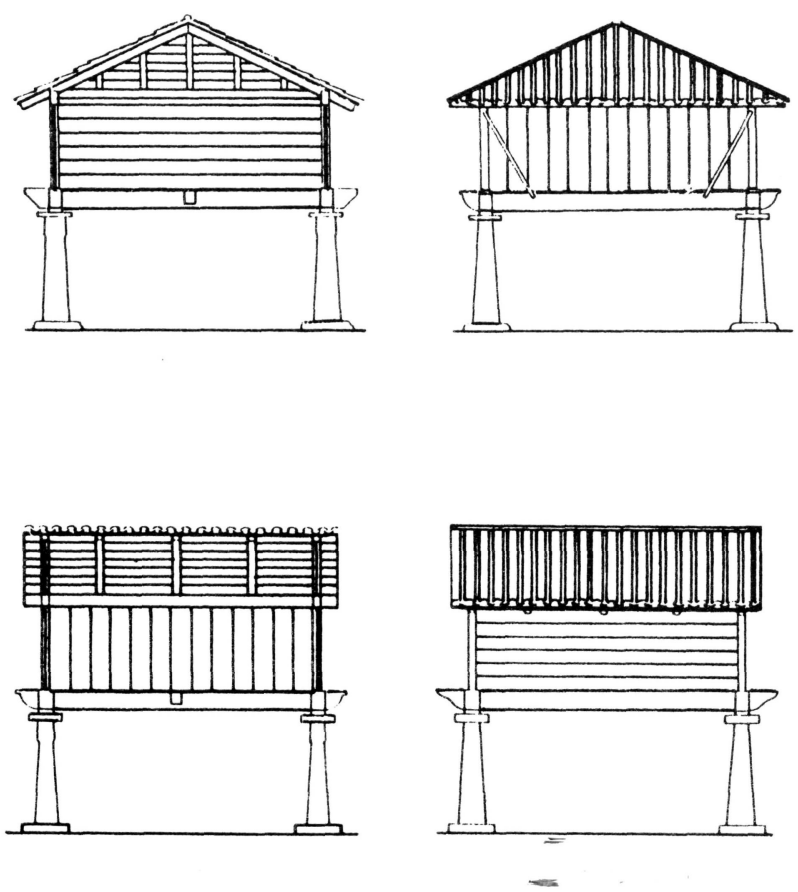

Fig.10.- Hórreos-tipo del valle de Valdeón (León): planta, alzado y sección. Autor 


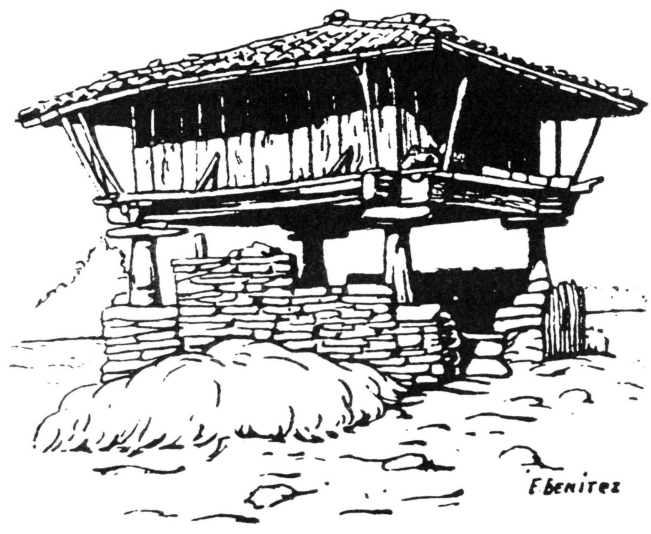

Fig.11.- Hórreo asturiano. Frankowski, E. - Op. cit. tuvo siempre comunicaciones más fáciles con Asturias a través de los ríos Sella y Cares, que con la meseta y León por los puertos de Panderruedas y Pandetrave, cerrados en época invernal).

La datación de los ejemplares existentes es imprecisa, si bien los más antiguos pudieran tener dos o tres siglos, el resto es del siglo pasado y los más recientes del presente siglo. Los últimos hórreos se construyeron en el valle en los años cincuenta, poco antes del inicio del procesoya señalado de emigración y despoblamiento del valle.

En cuanto a su implantación sobre el terreno (Fig. 12), lo más frecuente es su disposición próxima a la vivienda,

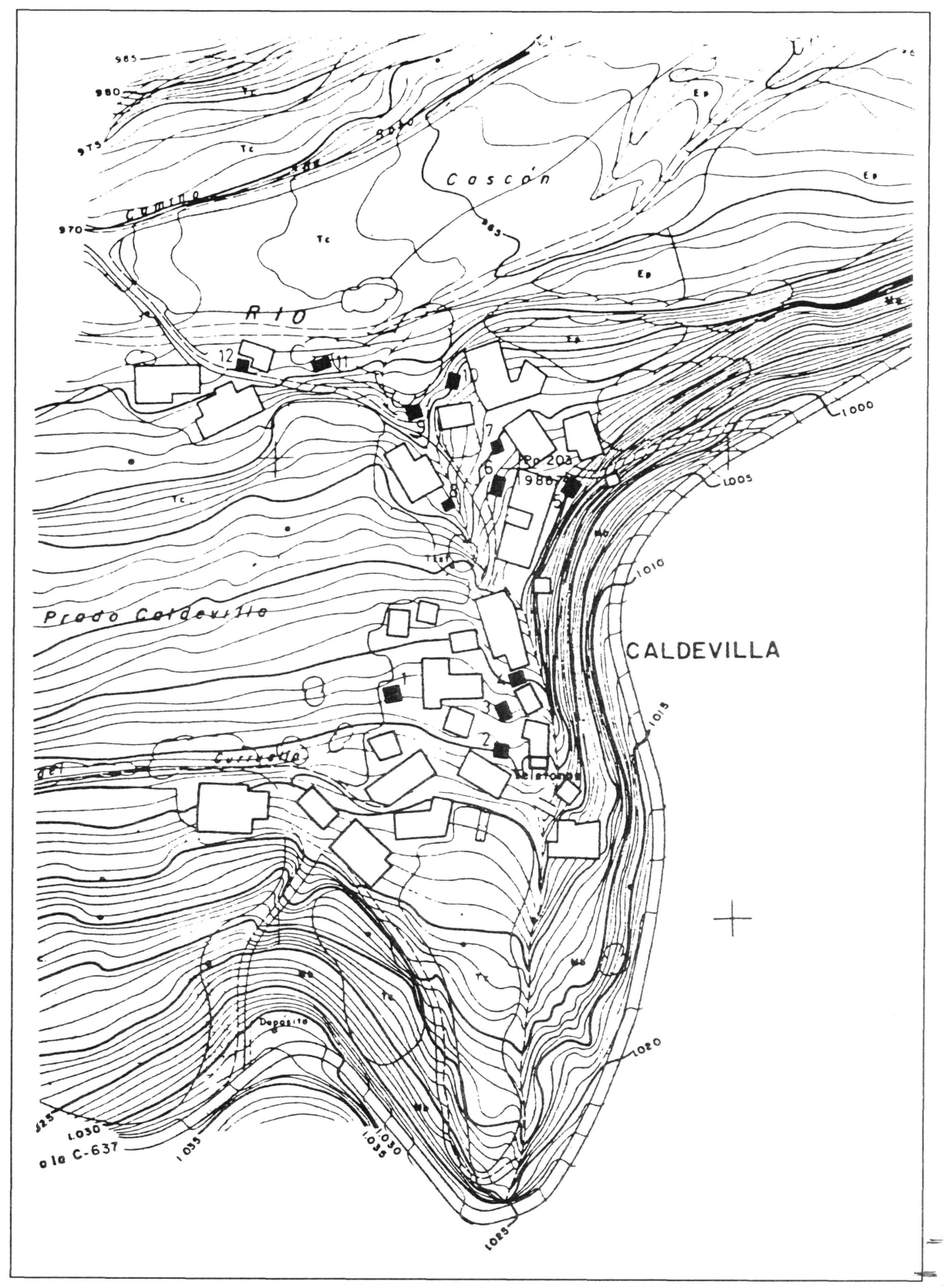

Fig.12.- Localización de hórreos en el núcleo de Caldevilla,valle de Valdeón (León). Autor. 
siendo raras las agrupaciones de hórreos, que cuando aparecen se deben más bien al azar de la coincidencia en la disposición, orientación y disponibilidad de terreno libre de las parcelas, caracterizando en estos casos fuertemente el entorno inmediato (hay que tener en cuenta el gran número de ejemplares desaparecidos, lo que impide establecer leyes generales sobre este extremo).

\section{2 - Proceso constructivo con terminología, materiales y dimensiones de piezas. (Figs. 8, 9, 13 y 14).}

Se describe a continuación el proceso constructivo de los dos sub-tipos, diferenciado únicamente en la ejecución de la cubierta.

Efectuado el replanteo de la planta del hórreo (con dimensiones que varían de 3,50 a 5,50 m de lado), se colocan las basas o cimientos en sus esquinas (soleras), normalmente grandes piedras de río (con diámetro aproximado de 50 a $70 \mathrm{~cm}$ ) o en su defecto, piedras de extracción directa desbastadas, colocando sobre ellas los pies derechos (pegollos) que sustentarán el hórreo. Se prefieren las soleras de canto de río por la curvatura superior de las mismas que garantizan una mejor unión y estabilidad del conjunto solera-pegollo y una inmediata evacuación de las aguas pluviales, aunque exigen un cuidadoso trabajo de la base del pegollo para garantizar un buen asentamiento.

Los pies derechos de sujeción del hórrreo (pegollos) son normalmente de forma tronco-piramidal con las esquinas achaflanadas (de dimensiones aproximadas de 1,30 a 1,80 $m$ de altura y unos 40-45 cm de sección en la base y 25-35 $\mathrm{cm}$ en coronación), habitualmente de roble (madera empleada en todos los elementos del hórreo; en su defecto, castaño) y en algunos casos de piedra caliza (la habitual de lazona) trabajada con puntero. Aunque estaúltima variante supone una alteración del siglo actual en los materiales tradicionales del hórreo, son evidentes las ventajas a efectos de conservación y durabilidad. El corte de la madera de roble se hacía antiguamente con hacha y azuela y en la actualidad con sierra de cinta en taller o motosierra en obra.

Sobre los pegollos bien aplomados se colocan piedras de forma circular (en ocasiones de moler) y dimensiones aprox. de $60-85 \mathrm{~cm}$ de diámetro con grosor de $10-20 \mathrm{~cm}$ (torna-ratas) que impiden el acceso al hórreo a los roedores y alimañas a través de los pegollos. Sobre esta base se coloca un bastidor formado por cuatro vigas (traves) de sección aproximada de $15-30 \mathrm{~cm}$ de anchura y 30 a $40 \mathrm{~cm}$ de altura, con longitud que excede la planta del hórreo en 50-60 cm por ambos lados, enlazadas dos a dos (par inferior y superior) a media madera y con los extremos formando unos pequeños voladizos acabados con diversas formas.
Este bastidor se nivela mediante unos tacos de madera (calzos) de aprox. 20-30 x 20-25 cm y altura variable según lo exija la nivelación (de $3-15 \mathrm{~cm}$ ), colocados sobre los torna-ratas. Además de su función específica cumplen una importante función estética(al proporcionar mayor esbeltez al conjunto del hórreo) y de diferenciación entre los elementos sustentantes (pegollos) y sustentados (caja) del hórreo.

En los extremos en vuelo de los traves se suele apoyar el tablón o escaño para acceso al hórreo (tanobia o tenobia), de $5-7 \mathrm{~cm}$ de grosor y $20-40 \mathrm{~cm}$ de anchura, siendo habitual la colocación de un apoyo intermedio, para evitar la excesiva flecha que en su defecto inevitablemente aparece.

El bastidor así formado constituye la base de sustentación de la caja o cuerpo del hórreo, presentando los traves profusión de rebajes y canaladuras para el encaje de otras piezas del hórreo. Entre éstas, la viga que parte la luz libre del suelo del hórreo (viga media) de sección aproximada de $20 \times 20 \mathrm{~cm}$ y que enlaza con los traves correspondientes en cola de milano o simple caja. En ocasiones la viga media no existe y en otras aparece además una segunda familia de sustentación formada por viguetillas de sección aproximada. de $7 \times 12 \mathrm{~cm}$. Las tablas del suelo de la caja del hórreo son de sección aproximada. de 3,5-7 x 20-30 cm y van alojadas en canaladuras o rebajes de una pareja de traves $y$, eventualmente, también en la viga media (en aquellas unidades pertenecientes a dos propietarios distintos, con tabique de separación interior).

Sobre esta plataforma se montan, en primer lugar, los cuatro pies derechos (cantoneras) de las esquinas del hórreo, de secciones aproximadas de 15-20 x 15-20 cm, con espigos en ambos extremos para alojarse en las correspondientes cajas abiertas en el par superior de los traves, aplomándose provisionalmente (o definitivamente si posteriormente no se retiran, lo que redunda en la mejor estabilidad del hórreo) mediante parejas de tornapuntas (o tirantes, según su forma de trabajo), clavados a los traves. Como ya se dijo, los ejemplares más antiguos no llevan cantoneras, entrecruzándose las tablas de cerramiento mediante rebajes superior e inferior en cada tabla, dispuestas horizontalmente. Se han encontrado muy escasos ejemplares con tablero de cerramiento vertical sin cantoneras, formándose en este caso las esquinas con tablas de sección en $\mathrm{L}$.

Se colocan a continuación los maineles de la (s) puerta (s) de acceso al hórreo y el entablado de cerramiento, con tablas dispuestas vertical u horizontalmente, encontrándose ejemplares con juntas de ranura y lengüeta, otros machihembrados, a media madera o simplemente a tope. Las tablas extremas encajan siempre en las canaladuras practicadas en los traves, cantoneras, maineles, etc. La dimensión de las tablas varía de $20 \mathrm{a} 35 \mathrm{~cm}$, con grosor de 3,5 a $5,5 \mathrm{~cm}$. 
La caja se remata con la colocación de otro bastidor de dos pares de vigas (sobre-traves) enlazadas a media madera, de sección aproximada $15-20 \times 15-20 \mathrm{~cm}$ y longitud algo menor que la de los traves, que presentan cajas en el par inferior para alojar los espigos superiores de las cantoneras y canaladuras para el encaje de los extremos superiores de los tableros de cerramiento. Este bastidor superior arriostra superiormente la caja del hórreo y recibe los elementos de la estructura de cubierta. A partir de aquí se diferencia el proceso constructivo de los dos sub-tipos:

\section{- Hórreo con cubierta a cuatro aguas (Figs. 9 y 14) :}

En los hórreos de cubierta a cuatro aguas aparecen en ocasiones unos pequeños tirantes de arriostramiento colocados a $45^{\circ}$ enlazando la cara superior de los sobretraves en la proximidad de las esquinas (charranchas), que impiden la apertura de dicho bastidor por empujes de las cuatro vigas de cubierta, al tiempo que permiten reducir la luz libre de estas vigas.

Parala formación de laestructura de cubierta (con pendiente variable entre el 35 y el $50 \%$ ), se tiende entre los puntos medios de un par de sobre-traves una viga de forma ligeramente curvada o apuntada (curbatón) con sección de $15-17 \times 15-17 \mathrm{~cm}$, que apoya sobre aquél con rebaje de simple espera y que presenta en su coronación una caja para alojamiento del tarugo o enano (puntal) de apoyo de las vigas de la cubierta. La forma curva de esta viga (en realidad arco), tiene por misión impedir el descenso del vértice de la cubierta, frente a la posible flecha que una viga pudiera presentar, obteniéndose de alguna rama o árbol de tronco torcido. En ocasiones (hórreos de menor dimensión), no aparece el curbatón ni el puntal correspondiente, confluyendo los cuatro aguilones en un tarugo de madera de sección $15-20 \times 15-20 \mathrm{~cm}$ y aproximadamente $30-40 \mathrm{~cm}$ de altura, que sobrepasa la confluencia de aquéllos para formar el asiento de la piedra de coronación de la cubierta. Los cuatro faldones de la cubierta se forman con las vigas esquineras (aguilones) de dimensiones entre 3,50 y $5,00 \mathrm{~m}$ con sección de $20 \times 20 \mathrm{~cm}$, sustentadas en el encuentro de los sobre-traves y en los correspondientes rebajes de espera practicados en las cuatro caras del tarugo antes mencionado.

Sobre este armazón de la cubierta se disponen los cabios (o cabrios) según la dirección de la línea de máxima pendiente y a distancias de $60-80 \mathrm{~cm}$, alojados en rebajes practicados en los aguilones y con someros rebajes de espera en el apoyo en los sobre-traves (en ocasiones los rebajes de espera se practican en estos últimos). Sus dimensiones varían de 2,50 a 3,50 m con sección de $12-15 \times 12-15 \mathrm{~cm}$, formando vuelos de 45 a $65 \mathrm{~cm}$. Los extremos libres de los cabios suelen atarse con unas tablas colocadas de canto y clavadas a aquéllos (mandiles) de sección 12-15 x 2,5$3,5 \mathrm{~cm}$. El tablero de cubierta se forma con una tabla ripia de 3,5 cm de grosor y 20-35 $\mathrm{cm}$ de ancho en los ejemplares actuales y de $3,5-5,5 \mathrm{~cm}$ de grosor en los antiguos, colocándose las tablas con junta a tope.

En los ejemplares más antiguos no aparecen cabios, disponiéndose tablones de mayor grosor $(5,5-7.5 \mathrm{~cm})$, colocados perpendicularmente al alero y sustentados directamente en los sobre-traves y en canaladuras practicadas en los aguilones.

La teja se coloca en seco, calzándose las canales con ripias de la propia teja y rematándose el vértice con una piedra circular de aprox. $30 \mathrm{~cm}$ de diámetro y $10-12 \mathrm{~cm}$ de grosor (loncha-cimera), sobre la que se coloca otra con forma cónica y $30 \mathrm{~cm}$ de altura. El vuelo de la teja sobre el tablero varía de 7 a $12 \mathrm{~cm}$.

\section{- Hórreo con cubierta a dos aguas (Figs. 8 y 13):}

En los hórreos de cubierta a dos aguas, el par de sobretraves de los laterales es de mayor longitud y sección que el de los hastiales o piñones, al ser el que recibe los cabios de cubierta y forma los vuelos de protección de aquéllos, en donde se sitúan los accesos al hórreo. La formación del armazón de la cubierta comprende la formación de los hastiales (picales), que se inicia con la colocación de unos pies derechos (puntales) de 12-15 x 12-15 cm de sección sobre los puntos medios de los sobre-traves de los hastiales (aplomándose provisional o definitivamente con unos pequeños tirantes-tornapuntas), cerrándose con tabla (de las mismas características y disposición que el cerramiento de la caja) y rematándose con las vigas de hastiales (de la misma sección que los puntales).

Sobre estos cierres de los piñones se apoya la viga cumbrera (cumbre), de sección $15-20 \times 20-30 \mathrm{~cm}$ y longitud aproximada. de 4,50-5,50 m. Esta viga presenta cajas de enlace sobre los espigos de los puntales y eventualmente rebajes de espera para los cabios. Entre la viga cumbre y los sobre-traves laterales se colocan los cabios con secciones, separaciones y vuelos similares a los descritos para el hórreo de cuatro aguas. Es común el atado de sus extremos libres con los mandiles. El tablero de cubierta y la cobertura con teja es en todo similar a lo ya explicado.

Lo descrito hasta aquí puede decirse que constituye el conjunto de componentes constructivos invariantes del hórreo en sí, existiendo una serie de complementos de presencia habitual pero no obligada :

-El muro de delimitación del espacio cubierto por el hórreo (aparece casi siempre), de mampostería concertada en seco u ordinaria, hecho con mortero de cal, de cemento o mixto. Su grosor es de aprox: $40-50 \mathrm{~cm}$ y su altura de aprox. $80-$ $140 \mathrm{~cm}$. El cierre se suele limitar a tres lados del hórreo.

-La escalera de acceso, de mampostería con peldaños enterizos de losas de piedra caliza desbastada o con la cara 


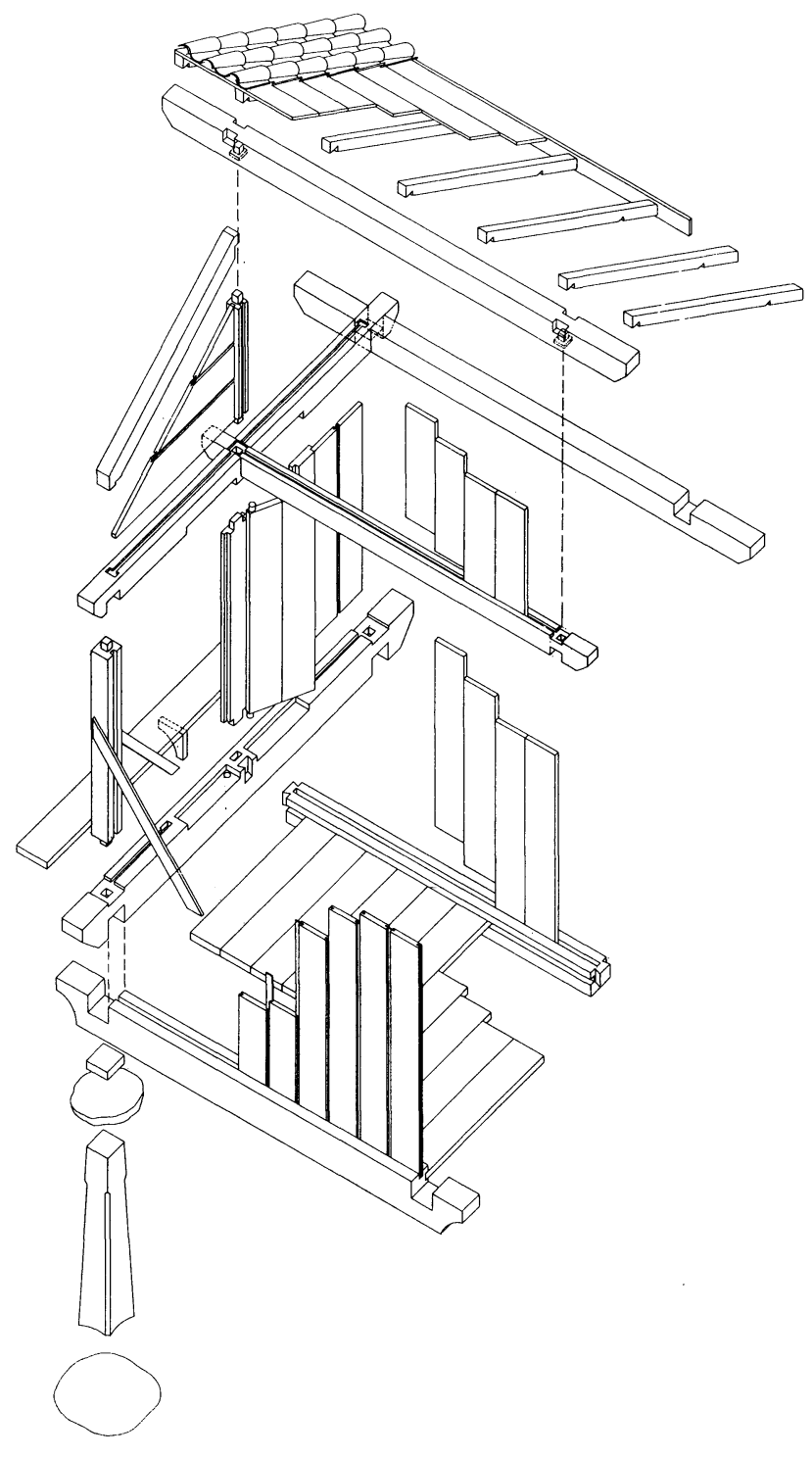

Fig.13- Hórreo-tipo de cubierta a dos aguas del valle de Valdeón (León) : despiece y ensambles. Autor.

superior y/o laterales trabajadas y dejando unos $30-50 \mathrm{~cm}$ de separación entre el último peldaño y la tanobia. Se presenta aislada o formando parte del muro delimitador. Son raros los casos en que no aparece, siendo entonces el acceso a través de escala móvil de madera.

-La galería frontal o perimetral, que aparece muy raramente, formándose el suelo de igual forma que la tanobia y

(c) Consejo Superior de Investigaciones Científicas Licencia Creative Commons 3.0 España (by-nc)

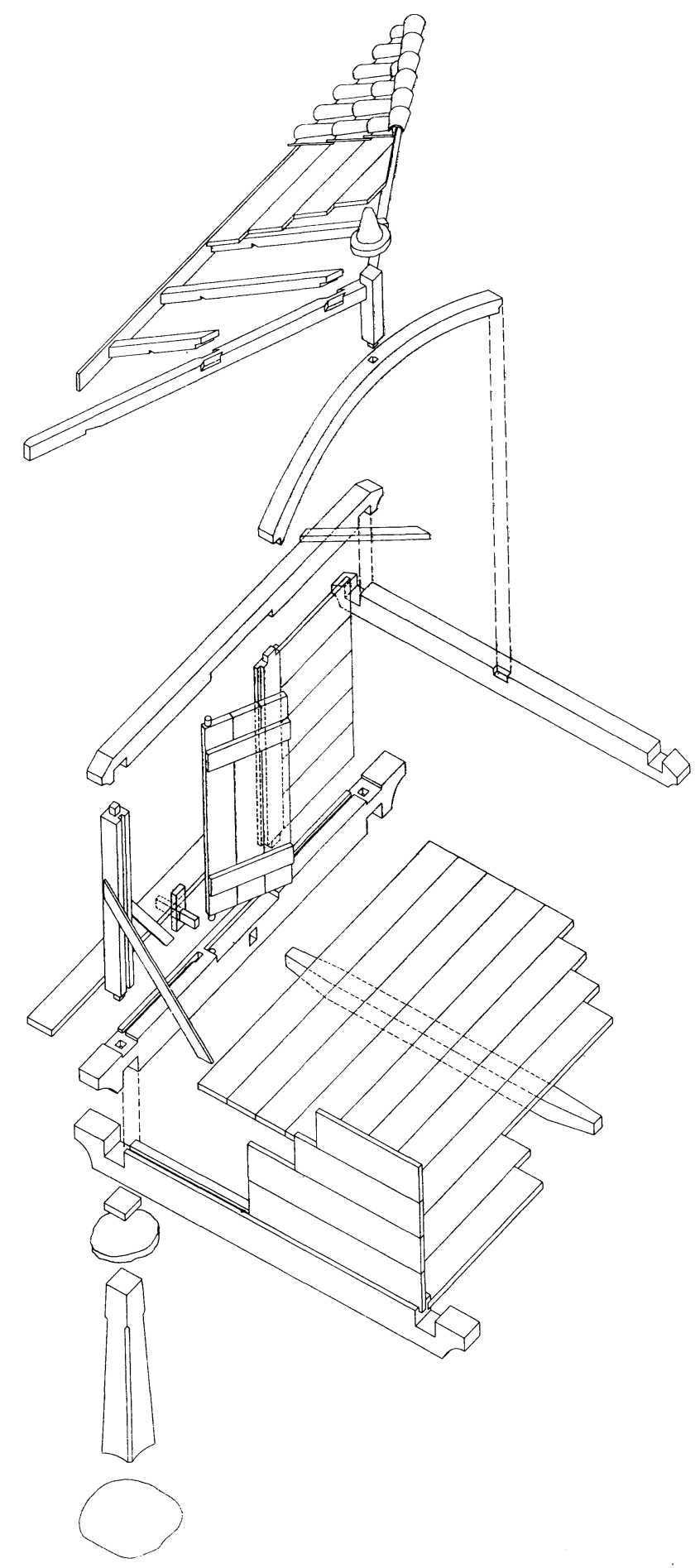

Fig.14.- Hórreo-tipo de cubierta a cuatro aguas del valle de Valdeón (León) : despiece y ensambles. Autor.

colocándose en las esquinas montantes fijados a los vuelos de los traves y aguilones, con sección de 5-7 x 5-7 cm, para fijación de un pasamanos o quitamiedos de la misma o similar sección. Se puede decir que constituye la expresión más elemental de lo que puede llamarse galería.

-

-El tabique de división interno (en caso de propiedad compartida del hórreo), formado por tablero similar al del 
cerramiento externo de la caja o con varas de avellano, tilo o roble y trenzado de ramas y tallos vegetales (en ocasiones, también con armazón de varales y plementería o relleno de mazorcas de maíz, al igual que los antiguos sistemas de tabiques y cerramientos de la edificación tradicional del valle).

-La decoración de los tableros de la caja del hórreo, únicamente vista en un ejemplar, consistente en motivos geométricos elementales (círculos y otras figuras geométricas inscritas, con asimilación a motivos vegetales).

\section{3 - Funcionamiento estructural}

Estáticamente hablando, el hórreo es una estructura (caja) semi-rígida (como manifiestan sus deformaciones progresivas) formada por un bastidor o armazón con el gradode hiperestatismo que le proporcionan los ensambles de sus piezas y el arriostramientode los tableros horizontales y verticales. Esta estructura se apoya (apoyo simple) en cuatro pies derechos, cuya baja esbeltez y acusada inercia, permiten el mantenimiento de la (relativa) estabilidad del conjunto isostático así formado.

Dicha estabilidad no se verá comprometida en tanto se mantenga el reparto uniforme de cargas sobre los cuatro pies derechos (lo que no es fácil, como se verá más adelante: deformación de la caja, de la sobrecarga, empujes del viento, etc), su verticalidad (lo mismo: pudrición de su base, etc.) y la ausencia de empujes horizontales (frente a los que el conjunto es una estructura-más bien mecanismosumamente inestable, dada la ausencia de empotramientos y arriostramiento de los pies derechos en el plano vertical). $\mathrm{Si}$ las condiciones iniciales se mantienen, una mayor sobrecarga del hórreo siempre implicará la disminución de las deformaciones. En frenar el proceso de caída desempeña un importante papel el contacto que los torna-ratas establecen con la cara inferior de los traves, en casos de deformaciones acusadas.

\section{4 - Patología y alteraciones constructivas.}

Las condiciones climáticas extremas de la zona (intensas pluviometría e innivación, heladas, vientos, fuertes oscilaciones higrotérmicas en los ciclos diario y anual) unidoa la caducidad del material y la falta de mantenimiento, originan el deterioro de los hórreos, dando lugar a una patología característica:

- Pudrición de elementos de madera.

Aparece preferentemente en el tablero y estructura de sustentación de la cubierta, siendo causada por las humedades de infiltración a través de la misma, por movimiento, caída o rotura de tejas por la nieve o por los sucesivos retejos. Aparece también frecuentemente en la base de los pegollos y extremos de los traves y, ocasionalmente, en los mismos traves, debidoa infiltración del agua por la junta con el tablero de cerramiento de la caja. El agente suele ser la carcoma y hongos de pudrición parda y blanca. En un gran número de ocasiones resulta dañada únicamente la capa superficial del elemento, conservándose sana la madera en el interior, aunque en los casos de extensión del ataque al interior sólo cabe la sustitución de las piezas.

\section{- Alabeo y/o deformación de elementos de madera.}

Provocados por la diferente orientación y exposición solar de las caras del elemento y / o del hórreo en su conjunto, por las fuertes oscilaciones termo - higrométricas, por la utilización de madera verde, constituyendo todos ellos factores que someten a las diversas secciones de las piezas a tensiones y deformaciones diferenciales, originando alabeos y giros de las piezas y provocando la aparición de fendas y agrietamientosen las mismas, tanto internas como superficiales, estas últimas, sobre todo, en los elementos de madera antigua y más expuestos (cabezas de traves, de cabios, tanobias, parte inferior de los pegollos, etc). La flecha excesiva en los elementos que trabajan a flexión es también habitual (cabios, traves, tablero de suelo, tanobias, etc). En general estas deformaciones no impiden a los elementos afectados seguir cumpliendo correctamente su función, por lo que no se consideran importantes (si se soslaya la alteración estética).

- Entornado de los hórreos y/o apertura de la caja (Fig. 15, arriba).

El primero no aparece en los ejemplares con pegollos de piedra, siendo muy frecuente en los de madera como resultado de la pudrición de la base de los pegollos, al reducirse el área útil de sustentación y convertirse el apoyo en una articulación que permite el giro del pegollo ante cuaquier solicitación externa. Estas pueden venir ocasionadas por cedimiento de una o más soleras, por descompensación de la carga del hórreo, por empujes fortuitos (carros, tractores, camiones, etc), por rotura de algún elemento sustentante (traves, etc), por presión diferencial del viento o la nieve, etc (las fases iniciales del proceso se explican en la parte superior de la figura de referencia, siendo habitualmente el entornado la combinación de dos o más de las deformaciones descritas).

Los torna-ratas actúan como elementos estabilizadores al hacer tope sus bordes con la cara inferior de los traves y en algunos casos los propietarios colocan algún punto de apeo. El hórreo no cae (salvo por la aparición de algún empuje horizontal que le haga girar sobre sí mismo), pero sus piezas se desajustan, apareciendo huetgos en las uniones que, con el tiempo, incrementan la-deformación. La importancia de este desperfecto viene dada por el grado de la deformación, aunque siempre es conveniente corregirla. 

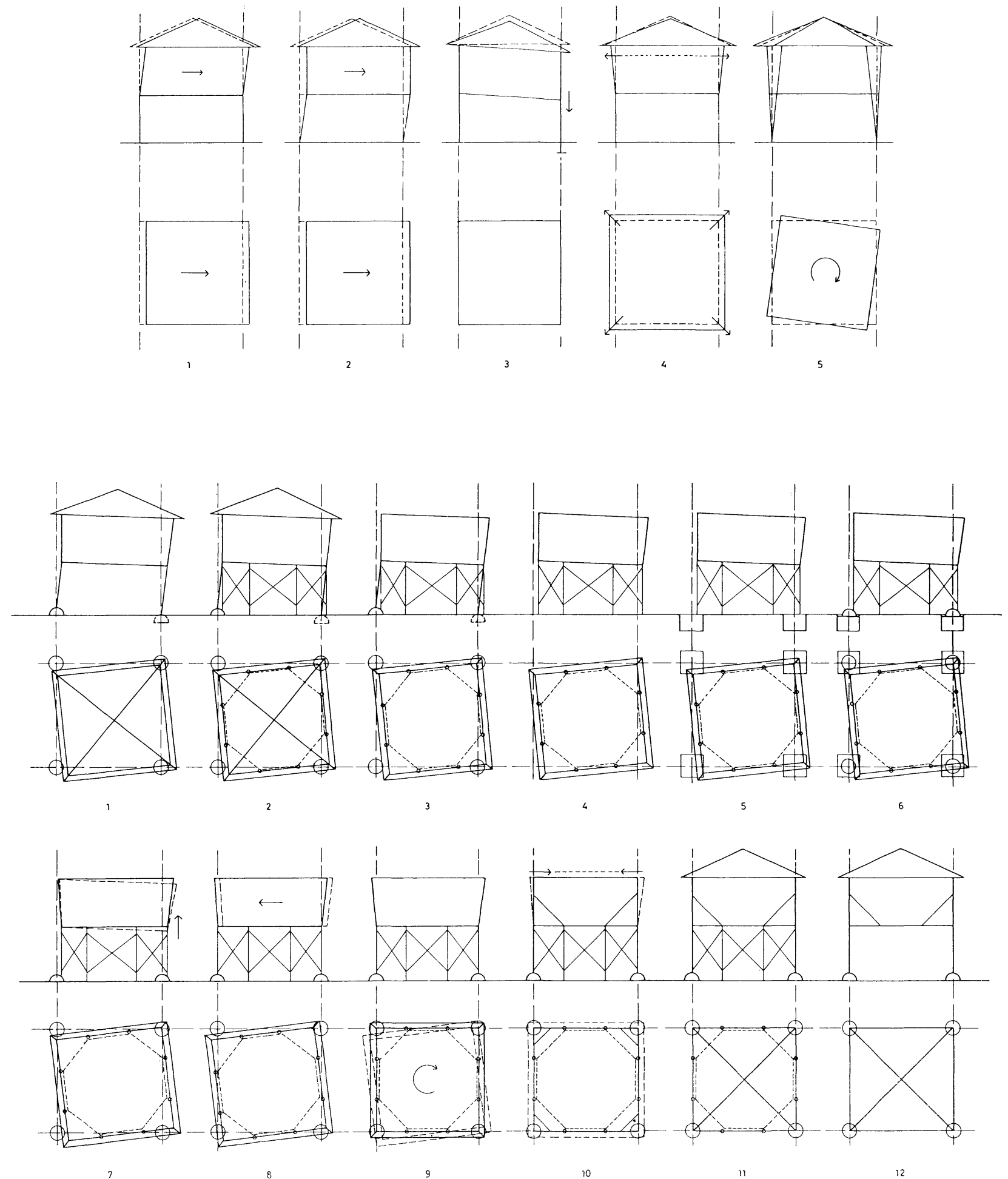

Fig.15.- Deformaciones-tipo básicas de los hórreos del valle de Valdeón (arriba). Proceso de corrección de deformaciones -entornado, giro y apertura de la caja- en un hórreo del valle de Valdeón (abajo). Autor.

La apertura de la caja es habitual en los hórreos de cuatro aguas, siendo causada por los empujes de los aguilones (por descenso del caballete ante el peso de la nieve y por la progresiva deformación del material) sobre las esquinas de la caja del hórreo. En muchas ocasiones no reviste mayor importancia que la alteración estética.

(c) Consejo Superior de Investigaciones Científicas Licencia Creative Commons 3.0 España (by-nc)

\section{- Rotura de piezas.}

No es habitual por la dureza del reble, constituyendo, cuando aparece, el final del proceso deformación antes mencionado en los eiementos flectados (traves, cabios, vigas medias,tanobias, etc.), por carga excesiva, sección 


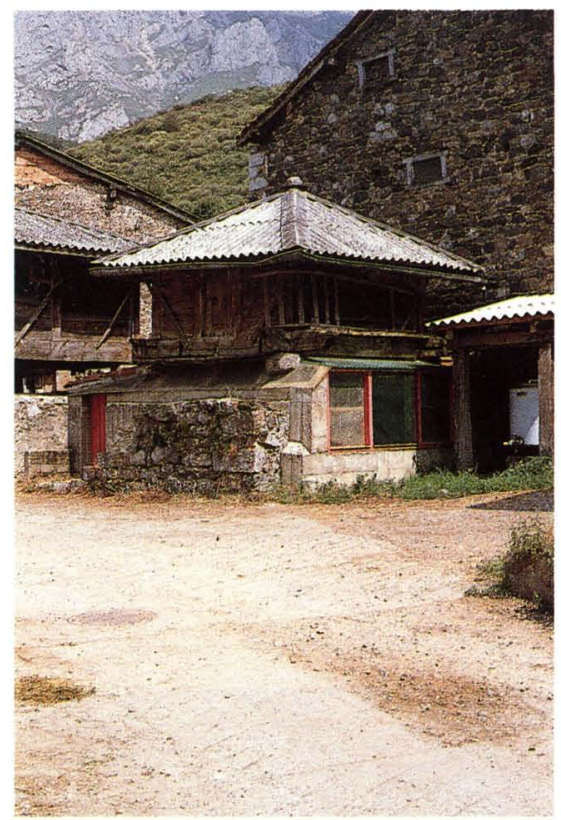

Fig.16.-Alteraciones del tipo: material de cubierta y tratamiento del espacio inferior. Autor.

\section{5 - Intervención realizada}

\section{1 - Criterios de la intervención.}

El criterio director de la obra ha sido eminentemente funcional y enfocado a la rehabilitación del mayor número posible de ejemplares: rehabilitación entendida en el sentido de subsanar los desperfectos existentes, sustituyendo las piezas inservibles, colocando apéndices en aquéllas que de esta manera podían seguir desempeñando su función (y evitando con ello su sustitución), consolidando o rehaciendo los muros deteriorados, aplicando productos protectores a la madera,etc, todo ello desde un punto de vista de los oficios intervinientes, como hasta los años cincuenta fue la norma en el valle. Se han considerado los hórreos por tanto como arquitectura "viva" (apesar de la pérdiday sustitución de su primitivo uso), que permite y requiere un mantenimiento tradicionalmente realizado por los artesanos y oficios del valle, utilizando para ello en cada época la tecnología disponible.

Se hahuido pues, de enfoques "puristas" (que podrían tener sentido en zonas con muy escasos ejemplares, no siendo éste el caso) que habrían limitado la actuación a un número exiguo de unidades (por evidentes razones de tiempo y presupuesto) y sentado las bases de una actuación de conservación fuera del alcance económico y técnico de los propietarios de los hórreos, que sin duda agudizaría el proceso de olvido y alejamiento más arriba comentado. Unicamente en los ejemplares de mayor antigüedad, con sistema constructivo, textura e imagen única e irremplazable, se intervino con un criterio más estricto de rehabilitación, evitando sustituciones y colocando los apéndices imprescindibles para evitar su ruina. En honor a la verdad, hay que decir que en un principio -cuando por la singularidad de la obra, los criterios de intervención no estaban tan claramente establecidos como con el transcurso de la misma llegaron a estar- no se hizo así en un ejemplar de estas características y con el que comenzó la actuación: lapuestaen cuestión del resultado, determinóel tratamiento singular de estos ejemplares especiales, confirmándose por lo demás como válido el criterio general seguido en la actuación (Figs. 17 - 18 y 19 - 20).

En coherencia con este enfoque (que podríamos llamar posibilista), se han utilizado materiales y medios auxiliares actuales (cemento, puntas de acero para uniones de piezas, teja cerámica de fábrica, apeos telescópicos, gatos para elevación del hórreo, tráctel de cable de acero, sierra manual de gasóleo, etc.). Se confía al paso del tiempo la integración de los elementos nuevos con los existentes y en lo referente a la formalización (despiece) de las piezas sustituidas y apéndices, no se ha-pretendido una reproducción exacta sino una "analogía formal"que 

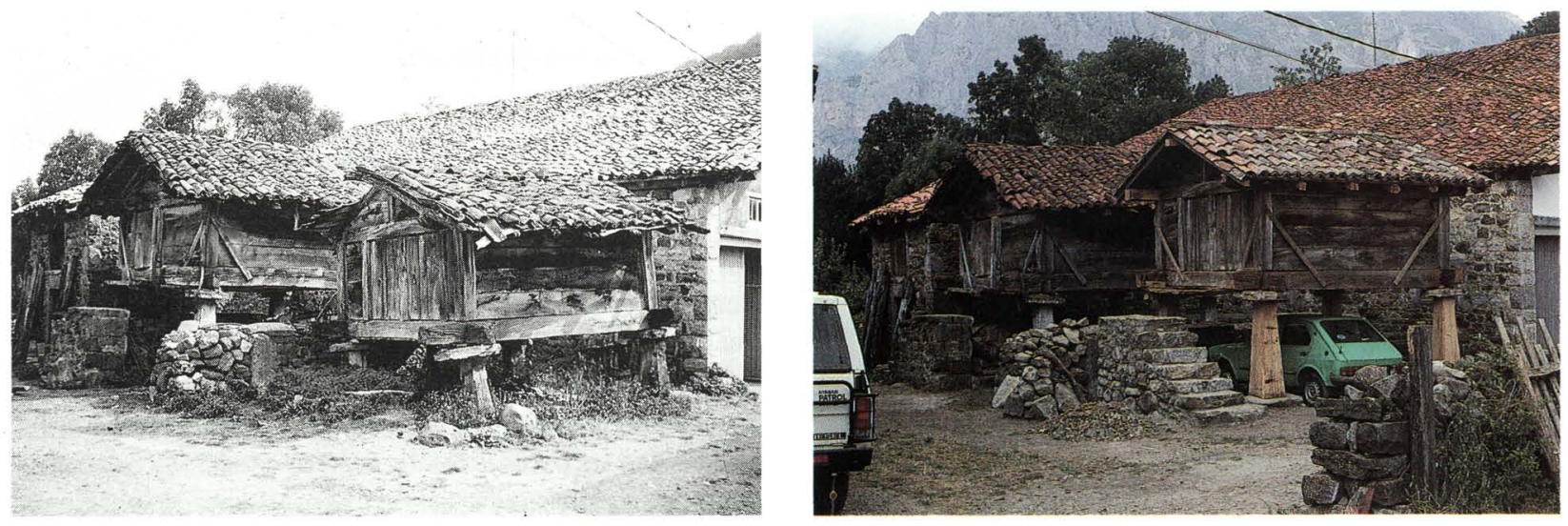

Figs. 17 y 18.- Hórreos antes y después de la intervención (izquierda y derecha resp.). Autor.
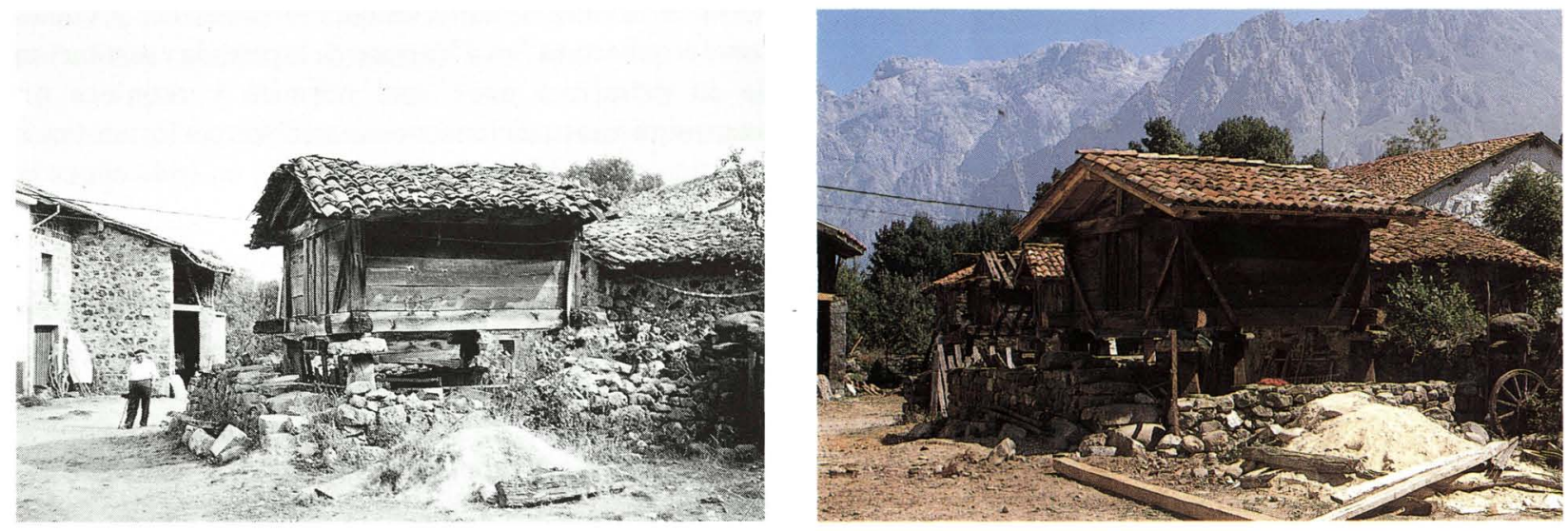

Figs. 19 y 20.- Hórreos antes y después de la intervención (izquierda y derecha resp.). Autor.

garantice la integración con lo existente mediante una restitución volumétrica de las piezas dentro de una cierta libertad formalizadora.

\section{2 - Ambito y cronología de la actuación.}

La intervención se llevó a cabo durante las campañas de 1988, 1989 y 1990 en Soto de Valdeón (15 unidades intervenidas) y Caldevilla (9 unidades). En el año 1991 se intervino en Posada de Valdeón (7 unidades) y en Los Llanos (8 unidades). Por último, en el año 1992, en Prada (8 unidades).

\section{3-Tipologíade las actuaciones: descripción constructiva.}

En función de la patología descrita en 4.4, aparecen una serie de intervenciones-tipo (o unidades de obra), que en base a su frecuencia y carácter, se pueden agrupar en cuatro grandes tipos :

-Aplomado de hórreos entornados con / sin recalzado de los mismos.
-Retejos de cubiertas con / sin intervención en el tablero de sustentación.

-Refuerzos, apéndices, sustituciones y añadido de piezas.

-Obras complementarias (limpieza del entorno, tratamiento de muros y escaleras y protección de la madera).

La actuación en las diversas unidades varía desde aquéllas queúnicamente precisaron un retejo hastalas que requirieron la gama completa de las actuaciones (afortunadamente las menos). Se describen a continuación estas intervencionestipo:

- Aplomado de hórreos entornados (explicación completa del proceso en Fig. 15, abajo).

En primer lugar se procede al apeo del hórreo (recomendable siempre y en todo tipo de actuación, por razones de seguridad ante cualquier descompensación o movimiento imprevisto del hórreo). Para ello se colocan dos puntos de apeo por trave próximos a los pegollos, atándose entre sí todos ellos con cruces de San Anđrés, formando un entramado espacial indeformable que permite trabajar con 
comodidad en las esquinas del hórreo (en este caso se hizo con puntales metálicos telescópicos que disponen de conectores para cualquier dirección y permiten aplicar presión diferencial en cada puntal (Fig. 21). Normalmente es necesario a continuación desmontar la teja, tablero y estructura de la cubierta (sólo en casos de ligero desplome puede corregirse sin hacerlo así), siendo obligado en los casos de apertura superior de la caja del hórreo y, desde luego, siempre conveniente por razones de seguridad (caída de tejas)y de facilidad para el movimiento del hórreo (menor peso), así como para el correcto ajuste de piezas y aplomado de elementos.

Por ser habitual la pudrición de la base de los pegollos (que como se ha explicado está en el origen del proceso de entornado), así como el asentamiento diferencial de los mismos, se procede habitualmente a su recalce : se igualan así las presiones en los cuatro apoyos y se transmiten a una capa del terrenoalgo más profunda, evitándose los posibles rellenos superficiales. Para ello se retiran primeramente torna-ratas, pegollos y soleras, aplicando presión a los puntales de apeo, quedando aquéllos libres y excavando a continuación pozos centrados con el plomo de los pegollos, de aproximadamente $80 \times 80 \times 60 \mathrm{~cm}$ que se rellenan con hormigón H-50 (eventualmente ciclópeo, incorporando grandesbolos) hasta cota $-100-15 \mathrm{~cm}$ respecto a la rasante. Antes del completo fraguado (y aprox. a las $24 \mathrm{~h}$. del vertido, dependiendo de la temperatura ambiental), se colocan las soleras y seguidamente los pegollos bien aplomados y con su base previamente saneada (Fig. 22). Como ya se dijo reviste una importancia fundamental para garantizar un correcto asiento y estabilidad del hórreo el buen ajuste de dicha base con la solera, trabajo que normalmente se realiza con la azuela. Se colocan a continuación los torna-ratas (que se izan entre varios operarios, dado el peso de los mismos, de 200 a $250 \mathrm{~kg}$ : (Fig. 23) y los calzos de nivelación de la caja del hórreo.

La corrección de la desnivelación vertical del hórreo se realiza mediante un gato mecánico sustentadoen borriquetas

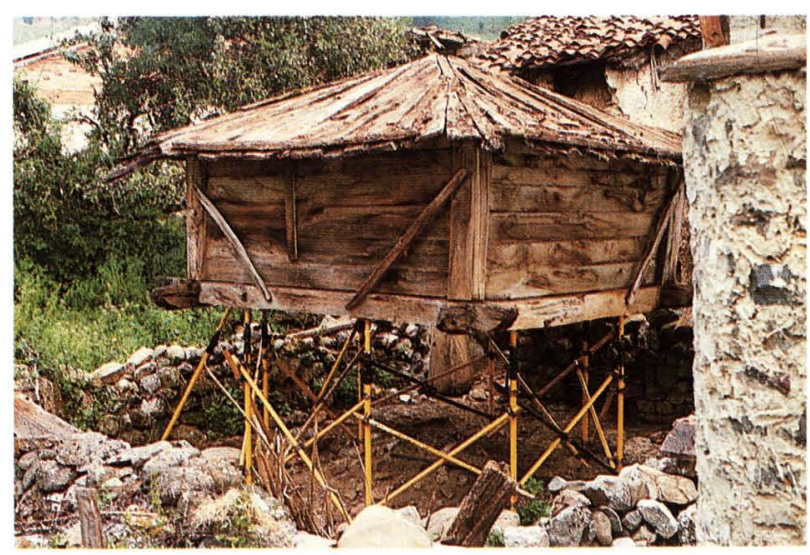

Fig.21.- Apeo de hórreo. Autor.

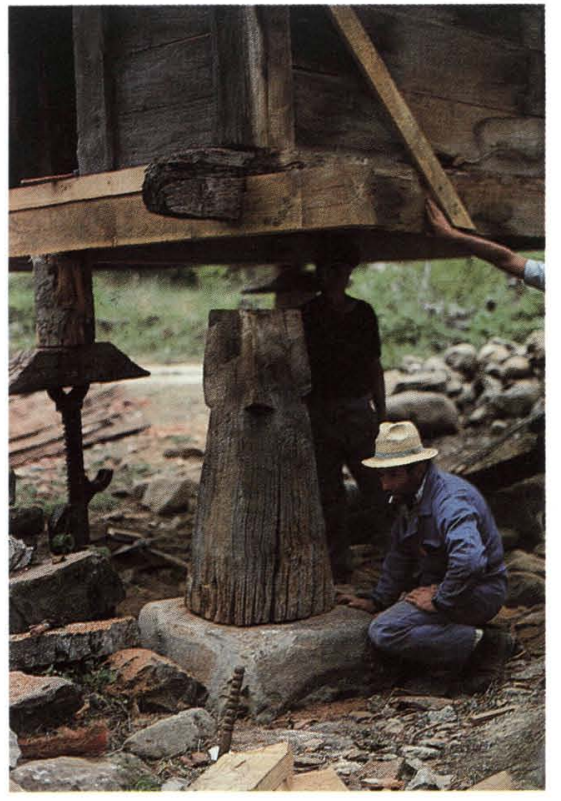

Fig.22.- Colocación y aplomado de un pegollo. Autor.

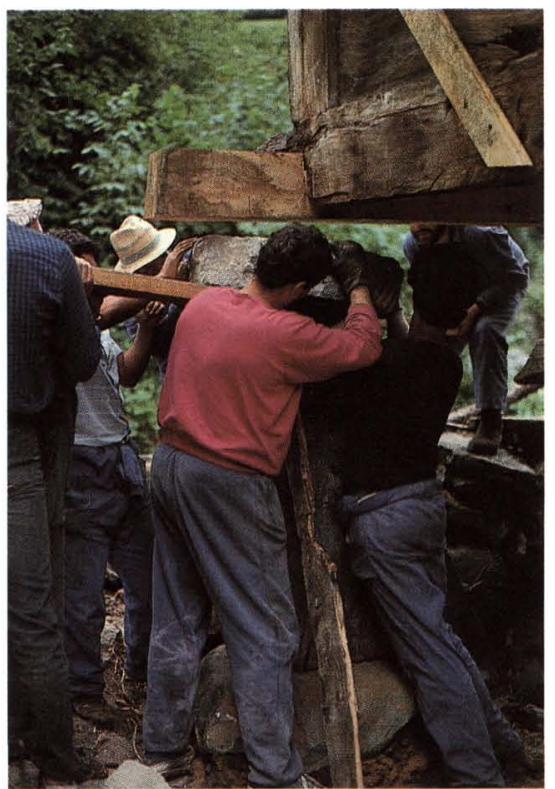

Fig.23.- Colocación de torna-ratas. Autor.

adecuadamente calzadas o suplementado con calzos de tarugos de madera. La corrección del reviro o giro del hórreo según el plano horizontal, se lleva a cabo forzando el movimiento mediante puntos de apeo aplicados a los sobre-traves o a las esquinas superiores de la caja del hórreo. La corrección de la apertura superior de la caja del hórreo, se lleva a cabo mediante cadenas traccionadas con un tráctel (máquina de accionamiento mediante palanca), que se pasan por los puntos medios de $\overline{\text { dos sobre-traves }}$ enfrentados(Fig. 24), rellenando los huelgos de las uniones de los mismos con tacos de madera y colocando los 


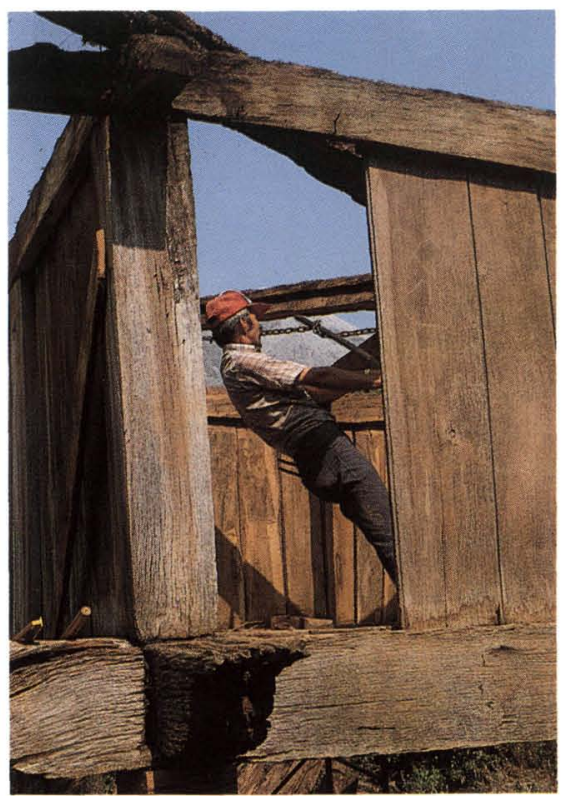

Fig.24.- Corrección de la apertura de la caja. Autor.

tornapuntas/tirantes de aplomado de las cantoneras. Como elemento de arriostramiento superior de los sobre-través se colocan en ocasiones (hórreos de gran dimensión o con caballete de escasa altura) tirantes a $45^{\circ}$ (charranchas) próximosa las esquinas. Se efectúan todas estas correcciones por etapas sucesivas hasta conseguir el definitivo aplomado del hórreo. En ocasiones resulta necesario suprimir alguna tabla del cerramiento o reducir la longitud de alguna pieza, para conseguir su buen ajuste en la nueva posición

- Retejo de cubiertas con / sin intervención en el tablero de sustentación.

Se trata sin duda de la intervención-tipo más habitual (realizada en la totalidad de los ejemplares en que se intervino). Se desmonta en primer lugar la teja (aprovechamiento medio del 20-40\%), limpiando la capa de asiento (tierra, nidos, ripias de teja, etc.) y a continuación se desmonta el tablero de tabla ripia, total o parcialmente (en ocasiones no resultó necesario, aunque fueron las menos). Se elimina la pudrición superficial de las tablas ligeramente dañadas con un cepillo de púas metálicas, procediendo en los restantes casos a su sustitución (en algún ejemplar-muy pocos-y por limitación del presupuesto se colocó tabla de pino norte). En bastantes casos fue también necesario proceder a la sustitución de cabios $u$ otros elementos del armazón de cubierta deteriorados.

La teja reaprovechada se limpia de líquenes y sustancias orgánicas, lavándose y colocándose mezclada con teja de aportación procedente de derribo. En ocasiones se utilizó teja cerámica nueva de producción industrial que dio mucho peor resultado debido a su escaso peso y mayor

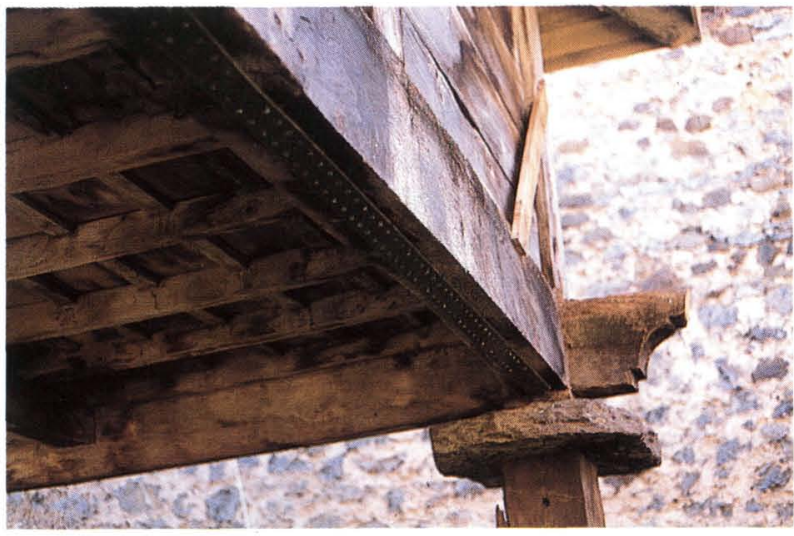

Fig.25.- Refuerzo inferior de trave con pletina de acero. Autor.

facilidad de deslizamiento ante el peso de la nieve (a ello también contribuye la colocación de tabla nueva, cortada en sierra y por ello con una superficie más lisa que la vieja). Esto se procuró evitar en sucesivos retejos y cuando no hubo otra alternativa, se colocó con un mayor solape dando así mayor peso al conjunto o bien mezclada con la reutilizada, dispuesta en cobijas. La teja se colocó siempre escantillada y en seco con la excepción de las limas y caballetes que se recibieron con mortero de cemento (son las tejas más expuestas y de caída más frecuente).

Para calzar la hilada de borde se utilizó un listón trapezoidal clavado en el borde del alero, se elevó ligeramente el mandil o se subieron las canales mediante cobijas intercaladas (que también actúan comocuñas) y doblado de las cobijas superiores. La formación de las limas fue habitualmente con una cobija, si bien también se desdobló en alguna ocasión interponiendo canal, siguiendo en todo ello esquemas ya utilizados en la zona.

- Refuerzos, apéndices y sustituciones de piezas.

En algún caso aislado fue necesario el refuerzo de piezas excesivamente deformadas oagrietadas, por la complicación y encarecimiento que su sustitución habría supuesto al implicar el desmontaje de todo el hórreo : como en el que aquí se presenta (Fig. 25), en que por tratarse de un trave cimero partido se reforzó inferiormente con una pletina de acero con múltiples puntas de acero a modo de conectores.

Se colocaron apéndices en aquellas piezas que presentaban pérdida de su sección en algún tramo de la misma, estando el resto en buenas condiciones de servicio: por ejemplo en cabezas de traves (frecuentemente con pudrición al ser elementos poco protegidos), vuelos de cabios y aguilones, maineles de puertas, etc. (Fig. 26). La ejecución de estos apéndices implica un cuidadoso trabajo que requiere el previocajeado de la parte dañada y su reprodución de forma tal que se garantice un perfecto acoplamiento de ambos, 
que se unen mediante encolado y clavado (o atornillado con barraqueros pasantes en elementos sometidos a mayores solicitaciones mecánicas).

Se sustituyeron todo tipo de piezas (traves, pegollos, aguilones, torna-ratas, tablero de cerramiento, tanobias, vigas medias, etc. (Fig. 26), en aquellos casos en que las soluciones anteriores no garantizaban un resultado satisfactorio desde el punto de vista funcional o estético. Huelga decir que la sustitución de un elemento "complicado" (como se dijo: traves, cimeros, cantoneras, etc) exige evaluar cuidadosamente la decisión frente a las soluciones anteriores, al implicar en algunos casos el desmontaje prácticamente total del hórreo (dado el sistema de uniones de sus piezas). El apeo previodel mismo en muchos de estos casos resulta obligado (realizado tal y como se explicó en el aplomado de hórreos entornados).

Por último, en algún caso aislado y por causas muy justificadas y singulares, se añadieron piezas nuevas al hórreo (pieza de apoyo intermedio de la tanobia, charranchas de sobre-traves, etc.): por ejemplo, en este caso (Fig. 27), se dotó al hórreo de una barandilla de la que carecía, al utilizarse el espacio inferior por uno de los propietarios como cocheray ser la copropietaria una señora anciana que requería protección en el acceso al hórreo (superpuesto al acceso del vehículo).

- Obras complementarias (limpieza del entorno, reparación de muros y escaleras y tratamiento de la madera).

La limpieza del espacio cubierto por el hórreo en las unidades abandonadas, se llevó a cabo por los participantes en los campos de trabajo (que también tuvieron asignadas

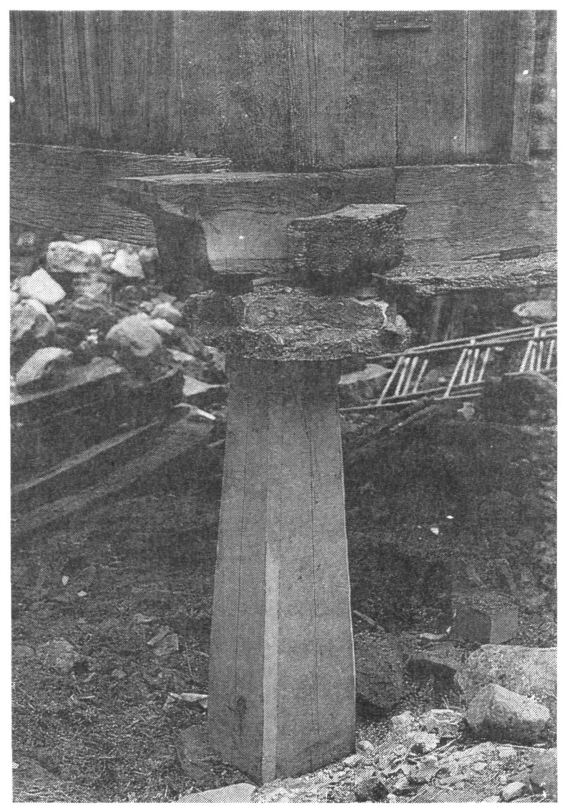

Fig.26.- Apéndice en extremo de trave y pegollo sustituido. Autor.

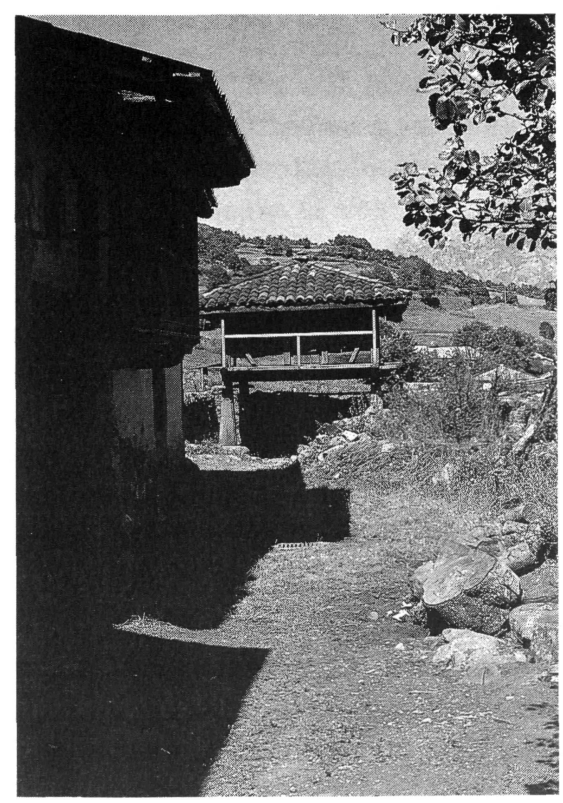

Fig.27.- Barandilla nueva. Autor.

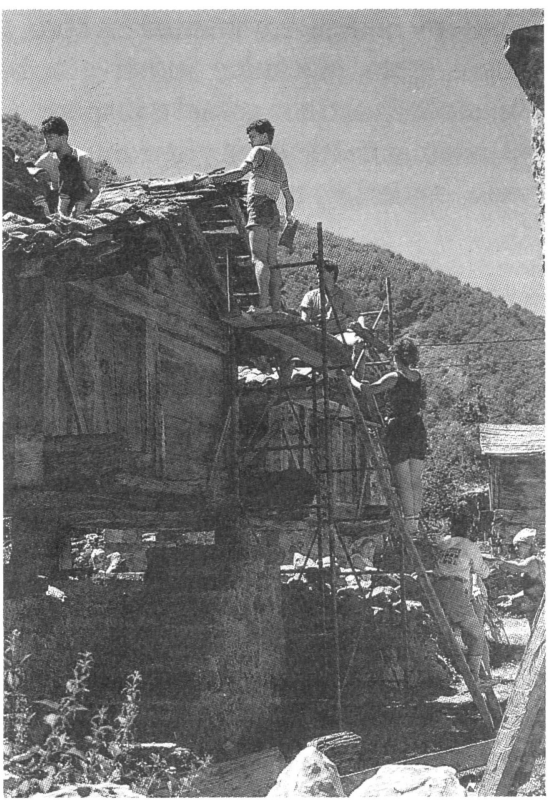

Fig.28.- Descenso de la teja de cubierta de un hórreo. Autor.

otras tareas como la protección de la madera, el descenso de las tejas de cobertura y el transporte de material (Fig. 28). Se aplicó un tratamiento de protección de la madera de todos los hórreos intervenidos.

Los muros delimitadores del espacio cubierto por el hórreo y las escaleras, se consolidaron o se levantaron de nuevo empleando la misma piedra del muro, colocada en seco en aquellos casos de cantos procedentes de larotura de piedras y tomada con mortero mixto de cal y cemento en los casos de bolos de lecho de río (Figs. 18 y 20). 


\section{4 - Materiales y medios auxiliares empleados.}

La madera empleada fue roble nacional aserrado de escuadrías similares a las piezas existentes (en ocasiones excesivamente verde, lo que originó la aparición de fendas en diversas piezas), con la excepción ya comentada del empleo de pino norte en algún tablero de cubierta. La piedra colocada, caliza procedente en su mayor parte de la cantera del vecino valle de Sajambre. En los casos restantes se empleó piedra de muros derruidos o se reutilizaron elementos de ejemplares derruidos o de derribo de edificaciones. El mortero, mixto de cemento, cal y arena en proporción $1: 0,5: 5$, el hormigón de recalces, $\mathrm{H}-50 \mathrm{y}$ composición en peso por $\mathrm{m}^{3}$ de $140 \mathrm{~kg}$ de cemento P-250, $160 \mathrm{~kg}$ de agua, $710 \mathrm{~kg}$ de arena y $1.420 \mathrm{~kg}$ de grava. La teja árabe, de derribo o de fábrica. Las puntas de uniones y tornillos barraqueros, de acero zincado. Como protección de la madera se aplicó una solución de petróleo, insecticida y fungicida o bien, aceite de linaza y secante.

En cuanto a medios auxiliaresy herramientas, se utilizaron andamios de un cuerpo y borriquetas habituales en albañilería, escaleras, puntales telescópicos de acero, sierra de cinta en taller y motosierra manual en obra, tráctel con cable de acero, gato mecánico móvil con bastidor de asiento, vehículo todo-terreno parael transporte de operarios y materiales, además de los útiles y herramientas habituales en carpintería, cantería y albañilería.

\section{6 - Conclusiones}

La singular experiencia de rehabilitación aquí descrita, permite extraer las siguientes conclusiones (que desde luego no suponen ninguna novedad, incidiendo en temas de todos conocidos : tampoco es la investigación el objetivo de este trabajo, sino la descripción de la intervención realizada) :

- Dentro de las circunstancias genéricas del ámbito en que se sitúa, se hace evidente la necesidad de clarificación de la figura legal de protección que en un futuro regirá en el valle y de su asunción por la población autóctona: es de suponer que ello influirá en el necesario cambio de mentalidadya apuntado, sobre la valoración de los elementos que caracterizan al valle y lo diferencian como una entidad específica susceptible de una explotación turística ordenada y controlada (es fácil imaginarse cuál sería la situación de estos hórreos en zonas similares de Austria, Suiza, Francia, etc). De ahí a la lógica toma de conciencia de su necesaria protección -entre los que los hórreos como tipo arquitectónico singular del valle se encuentran- no debería haber sino un paso. De no ser así, parece evidente que la desaparición de los mismos, no será más que una cuestión de tiempo. Se confirma pues, una vez más, el desinterés por la arquitectura y sistemas constructivos autóctonos y singulares, dentro del proceso general de aculturización social.
Naturalmente también podría continuarse la iniciativa rehabilitadora y de mantenimiento por parte de la Administración (cualquiera que ésta sea) -al ser elementos protegidos legalmente y declarados Bienes de Interés Cultural- bien por vía directa o por la indirecta de subvenciones y/oayudas a los propietarios. Esta posibilidad parece difícilmente asumible en una época de limitación generalizada de presupuestos e incremento del gasto por la ampliación de los ámbitos de las competencias públicas. Una intervención excesiva de la Administración, tiene además el inconveniente del paulatino desentendimiento de los propietarios, siendo quizá más positiva la vía de las subvenciones, préstamos o desgravaciones fiscales (como se hace en alguna Comunidad Autónoma), que permiten seguir implicándoles directamente en el mantenimiento y conservación de los hórreos.

- Es evidente la dificultad que presentan los antiguos tipos arquitectónicos complementarios a la vivienda y explotaciones agroganaderas, funcionalmente más especializados (como es el caso de los hórreos), para la sustitución de su uso al desaparecer el primitivo y por tanto, para poder seguir considerándolos "vivos", lo que supone un obstáculo importante para su futuro mantenimiento, a partir de la inexorabilidad de la ley que dicta la desaparición de la arquitectura que no se usa.

- Lo mismo cabe decir respecto a la sustitución de los materiales originales introduciendo otros nuevos (como lo demuestran las realizadas en algún ejemplar, ya comentadas), limitación fijada por la elementalidad del tipo y el mínimo número de sus materiales (madera, piedra $\mathrm{y}$ teja).

- Parece clara la necesaria flexibilidad en los criterios de toda intervención en el patrimonio construido. En nuestro caso y aún con un tipo tan elemental como es el hórreo de una zona perfectamente delimitada, distinguiendo entre los elementos más singulares (que podríamos llamar históricos, por su antigüedad y rareza) y la gran mayoría (procedentes casi todos del siglo pasado y del actual) y aplicar en consecuencia métodos de intervención diferenciados (según se explicó en 5.1).

- La aplicación de la legislación específica de proteccción también debería hacerse con un margen de flexibilidad, que permita a los propietarios (en ocasiones debidamente justificadas) la utilización del terreno ocupado por el hórreo para ampliación de la vivienda, etc. trasladando el hórreo a otra zona de la misma propiedad o en caso de no ser posible, a terreno cedido por el Ayuntamiento en las proximidades o en las afueras del núcleo (hay que tener en cuenta que en muchos casos no disponen de otro terreno), eventualidad que debería contemplarse en la Normativa de Planeamiento Municipal correspondiente.

- Aunque el costo de la actuación por unidad intervenida 
(aprox. 470.000 pts) resulta elevado, se ha de tener en cuenta que incluye el pago de una cuadrilla específicamente dedicada al trabajo así como de un coordinador y un director técnico de la actuación y supone una intervención "fuerte" en cuanto al importante número de hórreos con un acusado grado de deterioro intervenidos (que exigieron la sustitución de un buen número de piezas), no habiéndose realizado en muchos de ellos labores de mantenimiento desde mucho tiempo atrás. Una labor de mantenimiento periódica realizada por operarios autóctonos y sin técnicos directores (una vez sentados los criterios de la actuación), supondría sin duda una reducción considerable de costes.

De todos modos, no está de más tomar una vez más conciencia de que la rehabilitación y conservación (cuidadas), de determinados elementos arquitectónicos como el que nos ocupa, es cara y de bajo "rendimiento" económico(lo que en mayor o menor grado es de aplicación a toda la arquitectura patrimonial), siendo la sociedad la que debe decidir si está dispuesta a asumir el costo que ello conlleva.

- Para que la labor de mantenimiento arriba apuntada fuera posible, se hace necesaria la recuperación de los oficios tradicionales que la extensión de las nuevas técnicas constructivas ha hecho desaparecer (en ocasiones hubo serias dificultades para localizar carpinteros, siendo además frecuente el desconocimiento en profundidad de las técnicas de ensambles de la madera; no existen canteros en la actualidad en el valle). Que ello va ligado a la atención al ámbito rural para frenar la tendencia migratoria, parece fuera de toda duda (loque enlaza con la primera conclusión).

\section{BIBLIOGRAFÍA CONSULTADA}

FRANKOWSKI, E. (1986). "Hórreos y palafitos de la Península Ibérica". Ediciones Istmo, Madrid.

COBO ARIAS, F., CORES RAMBAUD M., ZARRACINA VALCARCE, M. (1986). "Los hórreos asturianos: Tipologías y decoración". Principado de Asturias.

FEDUCHI, L. (1974). "Itinerarios de arquitectura popular española". Editoriales Blume y Labor, Barcelona.

FLORES, C. (1973). "Arquitectura popular española". Editorial Aguilar, Madrid.

GARCÍA MERCADAL, F. (1981). "La casa popular en España". Ed. Gustavo Gili, Barcelona.

GÓNZALEZ ARPIDE, J.L. “Catálogo de hórreos de la provincia de León".

Actas del "I Congreso Europeo do Hórreo na Arquitectura Rural", celebrado en Santiago de Compostela, en Octubre de 1985.

Instituto Nacional de Estadística. Censo de población, 1991

\section{publicación del ICCET/CSIC}

\section{ACUEDUCTOS ROMANOS EN ESPAÑA Carlos Fernández Casado \\ Prof. Dr. Ing. de Caminos, Canales y Puertos}

Esta publicación se compone de una serie de artículos, publicados en la Revista "Informes de la Construcción", en los cuales se hace un análisis de los acueductos romanos que existen en España y el balance de las condiciones de conservación en que se encuentra cada uno de ellos, incluyendo referencias históricas y literarias. Se ha ilustrado con la reproducción de la valiosa documentación gráfica que posee el prestigioso autor.

Un volumen encuadernado en couché, a dos colores, de $21 \times 27$ centímetros, compuesto de 238 páginas, numerosos grabados, dibujos, fotos en blanco y negro y figuras de línea.

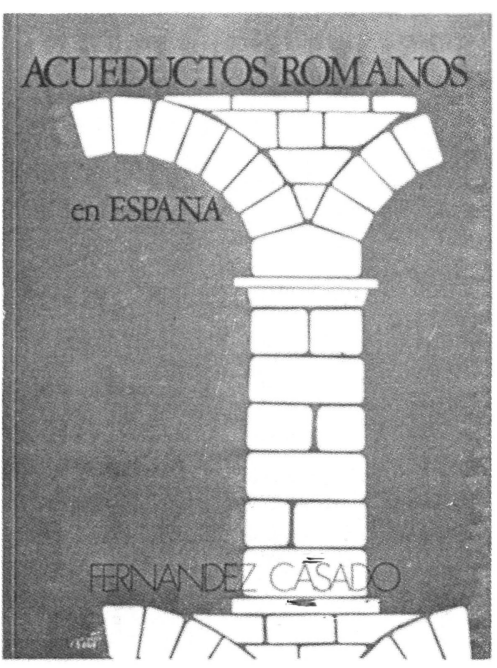

